UNIVERSIDADE ESTADUAL PAULISTA FACULDADE DE MEDICINA VETERINÁRIA E ZOOTECNIA CAMPUS DE BOTUCATU

\title{
"DESEMPENHO, CARACTERÍSTICAS DE CARCAÇA E ATRIBUTOS DA CARNE DE BOVINOS JOVENS CONFINADOS SUPLEMENTADOS COM VITAMINAS D E E"
}

SAMIRA RODRIGUES BALDIN

Dissertação apresentada ao Programa de Pós-Graduação em Zootecnia, como parte das exigências para obtenção do título de Mestre.

Janeiro - 2010

Botucatu - SP 
UNIVERSIDADE ESTADUAL PAULISTA

FACULDADE DE MEDICINA VETERINÁRIA E ZOOTECNIA

CAMPUS DE BOTUCATU

\section{"DESEMPENHO, CARACTERÍSTICAS DE CARCAÇA E ATRIBUTOS DA CARNE DE BOVINOS JOVENS CONFINADOS SUPLEMENTADOS COM VITAMINAS D E E"}

SAMIRA RODRIGUES BALDIN

Zootecnista

Orientador: Prof. Dr. Mário De Beni Arrigoni

Dissertação apresentada ao Programa de Pós-Graduação em Zootecnia, como parte das exigências para obtenção do título de Mestre.

Janeiro - 2010

Botucatu - SP 


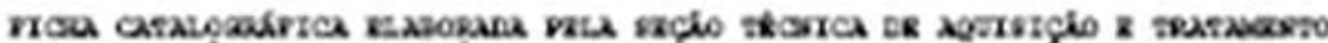

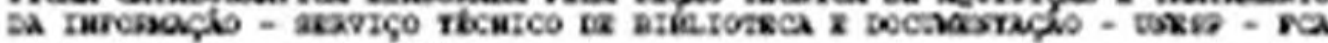
- Lacato - Dotrocaso (an)

\begin{tabular}{|c|c|}
\hline $2177 d$ & 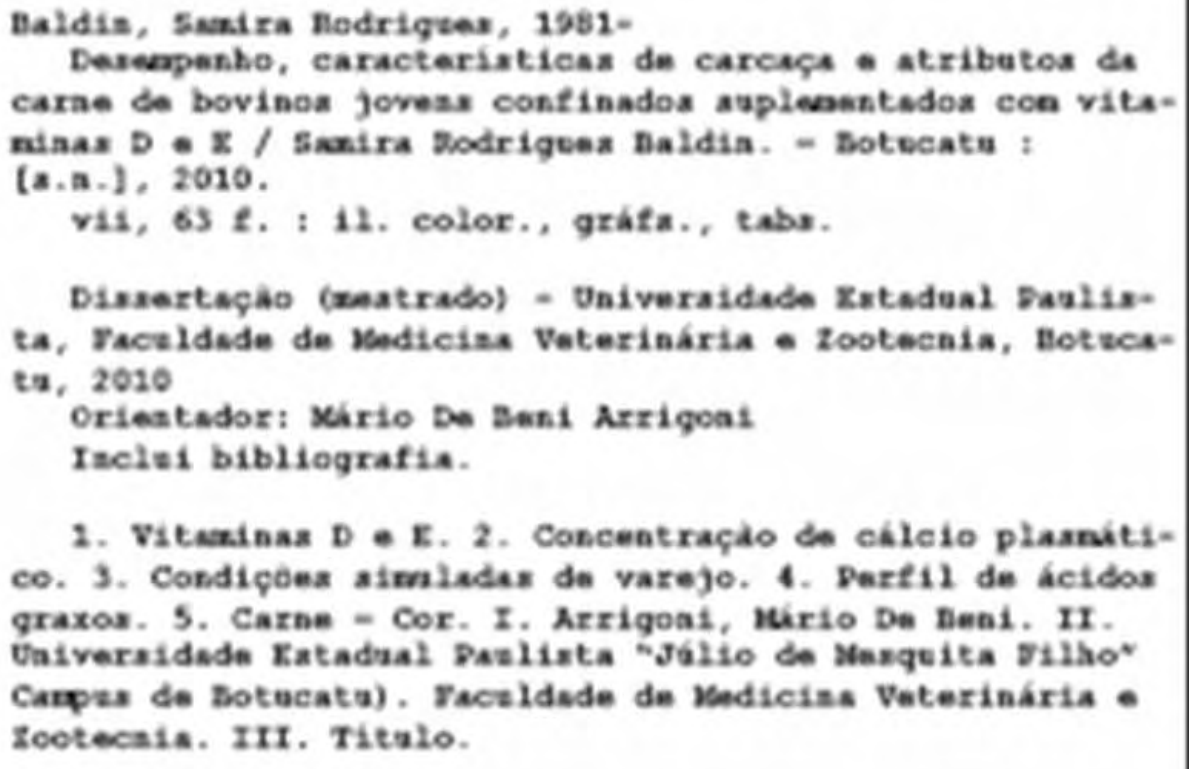 \\
\hline
\end{tabular}




\section{Dedico,}

Aos meus pais, "ALIR e JUREMA", que sempre estiveram do meu lado, participando e principalmente me apoiando, nunca me deixando desistir, por mais difíceis que fossem os caminhos. Agradeço a eles, pelas oportunidades que me proporcionaram, pela pessoa que me fizeram ser e pelo amor incondicional demonstrado.

A minha irmã “MAÍRA”, que sempre esteve presente, guiando meus passos, me apoiando, sendo uma incentivadora, excelente companheira e uma grande amiga.

A minha tia “ZULEICA”, pelo carinho, compreensão, amor e cumplicidade.

Ao meu namorado "PEDRO", que sempre foi um maravilhoso companheiro e acima de tudo um amigo, sempre paciente e dedicado, um exemplo de caráter e honestidade. Agradeço a ele por fazer parte da minha vida, tornando-a mais feliz.

"O segredo para viver em paz com todos consiste na arte de compreender cada um segundo a sua individualidade." 


\section{Ofereço,}

A Deus, por me ter proporcionado o dom da vida e sempre ter me guiado pelos caminhos certos.

\section{Agradeço,}

Ao Prof. Dr. Mário De Beni Arrigoni, primeiramente por ter me acolhido novamente em Botucatu, pela oportunidade, confiança e acima de tudo, pela orientação, companheirismo, ensinamentos e dedicação.

A Profa. Dra. Cyntia Ludovico Martins pela co-orientação, companheirismo, ensinamentos e dedicação, sendo muitas vezes, muito mais que uma co-orientadora. Uma incentivadora, sempre compartilhando comigo todas as questões, dúvidas e problemas que surgiram durante a condução deste mestrado. Obrigada por tudo!!!!

A Profa. Dra. Angélica Simone Cravo Pereira, por dedicar parte do seu tempo para me ajudar, pelos ensinamentos e principalmente pelas palavras, além da infinita contribuição para a melhoria deste trabalho. Agradeço também, os alunos da Profa. Angélica, pela ajuda na condução das análises em Pirassununga.

Ao Prof. Dr. Saulo da Luz e Silva, pela dedicação e contribuição, para a melhoria deste trabalho.

A Profa. Dra. Margarida Maria Barros pelas palavras, incentivo, apoio e dedicação.

Aos funcionários da Seção de Pós-graduação - Posto de Serviço/Lageado, Seila Cristina Cassineli Vieira, Danilo José Teodoro Dias e Carlos Pazini, pela compreensão e paciência.

Ao funcionário do Laboratório de Bromatologia, Renato Monteiro da Silva Diniz e a estagiária Janaína, pela colaboração na realização das análises.

As funcionárias do Laboratório de Análise de Perfil de Ácidos Graxos da Esalq, Maria Antônia e Carol, pela dedicação e apoio na condução das análises.

Aos amigos, João Paulo Franco da Silveira e Vivian Lo Tierzo pela amizade, companheirismo, apoio, conselhos, risadas, lágrimas, almoços, jantares, passeios, churrascos, momentos felizes e tristes que compartilhamos.

Ao amigo, Danilo Millen, pelos inúmeros momentos divertidos e cansativos que passamos discutindo o projeto, pela ajuda na condução do experimento, realização das 
análises estatísticas, entre outras inúmeras coisas que me ajudou. Principalmente, pela paciência e acima de tudo pela amizade demonstrada todo este tempo.

Aos amigos, João Paulo S. T. Bastos e Rodrigo Dias Lauritano Pacheco pela amizade, companheirismo, paciência e dedicação, pessoas muito especiais.

A Carla de Andrade, amiga, companheira, uma pessoa esplêndida, "amizade para o resto da vida". Esteve sempre presente e compartilhando momentos importantes da minha vida, incentivando, mesmo que longe.

A Juliana Paez, pela amizade, palavras, carinho e pelos momentos divertidos e inesquecíveis que passamos juntas em Botucatu.

As amigas de Pós-Graduação, Amanda Panichi, Ticiany Maria Dias Ribeiro, Andressa Natel, Taenna Martins Mariani, Carla Gisely e Carol Tobias pela amizade e carinho.

Aos amigos, Luis Marcelo Nave Sarti e Robson Sfacciotti Barducci, pela dedicação e empenho na condução do experimento, pelo companheirismo e acima de tudo pela amizade.

A todos os estagiários do confinamento, especialmente ao Diogo Tomazella, João Ricardo Ronchesel, por serem muito dedicados, além de amigos.

Em especial, aos estagiários do meu projeto, e hoje excelentes amigos, Nara Cônsolo e Fernando Parra, pois sem eles não teria conseguido nada. Principalmente pela amizade demonstrada e por terem compartilhado comigo inúmeros momentos bons e ruins que passei durante este período. Agradeço profundamente, por tornarem possível a realização deste trabalho sendo prestativos, dedicados e competentes acima de tudo.

A Tatiana Bula, pela ajuda na condução do primeiro experimento, pela força e dedicação, pelos momentos divertidos que passamos juntas no confinamento e acima de tudo pela amizade.

Aos funcionários do setor de Confinamento: Cido, Dinho, Claudemir e Sidnei pela dedicação, empenho e amizade, pessoas que fazem nos perceber quanto algumas pessoas são especiais na forma de ser e como são bem vindas as suas ações.

A Janaína Conte Haldlich, pela ajuda na condução das análises, ensinamentos e pela amizade. 
A Edwa Maria Bucuvic, uma pessoa iluminada, de um coração enorme, por sempre ter sido mais que uma companheira de república, uma irmã e amiga e por nunca ter desistido da nossa amizade.

Ao meu cunhado Mario Henrique Ferreira do Amaral Dall Pogetto, pela amizade, pelo incentivo e colaboração.

Aos professores Roberto de Oliveira Roça e André Mendes Jorge, pelo empenho e dedicação, pois fizeram parte da minha banca de qualificação e assim, contribuíram para a melhoria deste trabalho.

A Fapesp, agência financiadora do projeto e pela bolsa de mestrado oferecida durante toda a pesquisa.

Por fim, a todas as pessoas que direta ou indiretamente contribuíram para que eu conquistasse tudo que eu conquistei até hoje. Muito obrigada!!!! 


\section{SUMÁRIO}

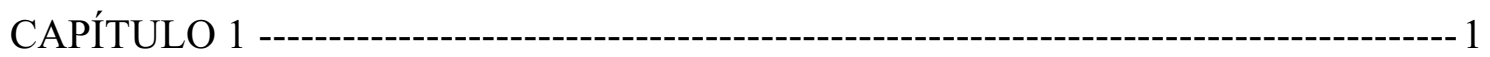

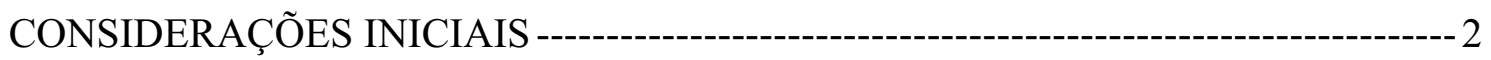

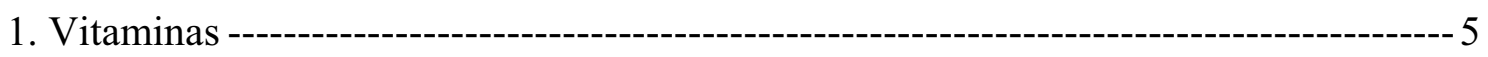

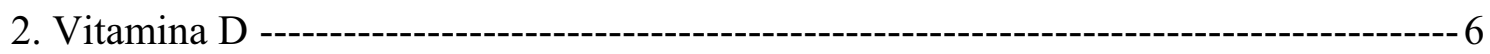

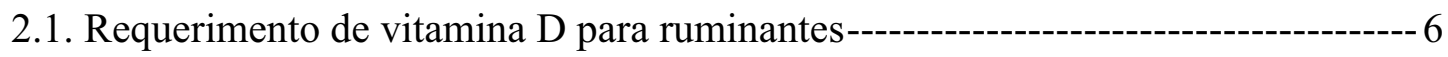

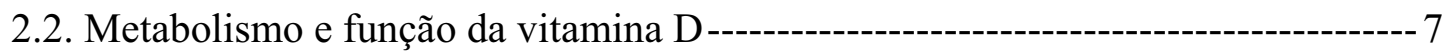

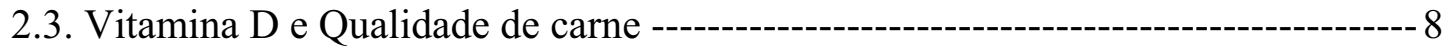

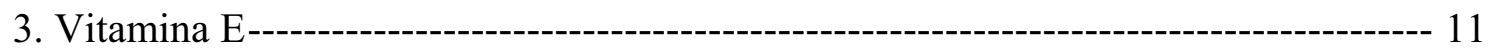

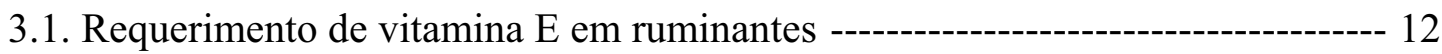

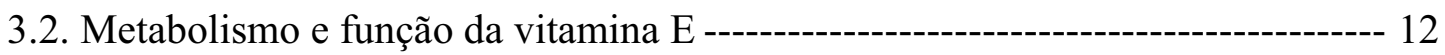

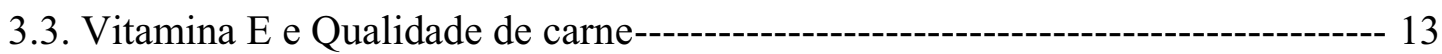

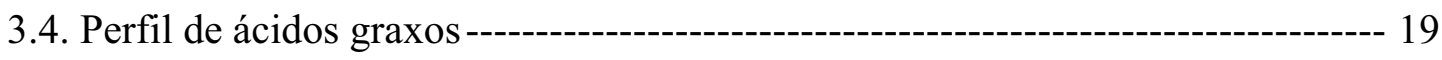

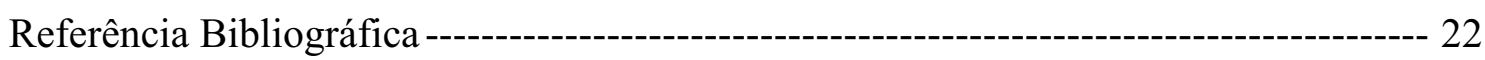

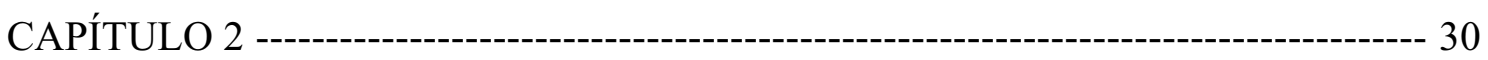

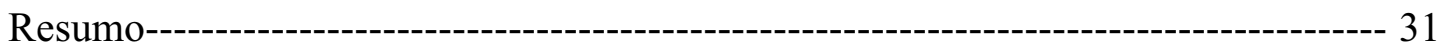

Abstract: -------------------------------------------------------------------------------------------- 32

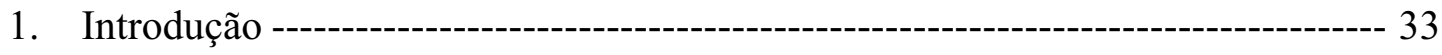

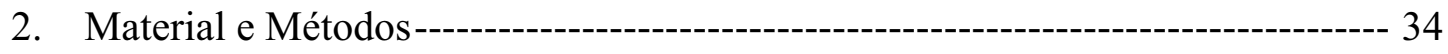

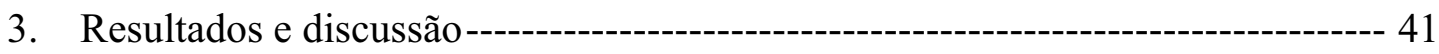

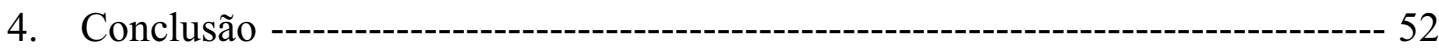

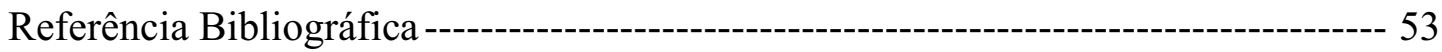

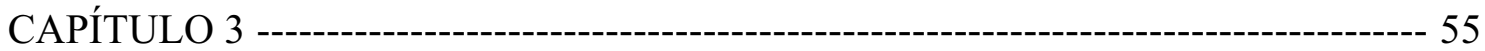

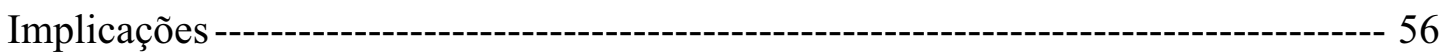


CAPÍTULO 1 


\section{CONSIDERAÇÕES INICIAIS}

O Brasil detém o maior rebanho comercial do mundo e atualmente é o maior exportador mundial de carne in natura. Ocupa o terceiro lugar no consumo mundial de carne bovina e o segundo em produção de equivalente de carcaça, perdendo somente para os Estados Unidos em volume produzido. O Brasil exportou no ano de 2009, 1,2 milhões de toneladas de carne, sendo que $67 \%$ foram in natura. Estes valores movimentaram a economia brasileira em U\$ 4 bilhões de dólares aproximadamente (ABIEC, 2009).

Neste contexto, a abertura do mercado brasileiro dentro do processo de globalização da economia, trouxe consigo a necessidade de competir com produtos de alta qualidade, que até então não faziam parte da realidade nacional. Em conseqüência dessa evolução da pecuária, em virtude do aumento das exportações de carne e a ampla exigência do mercado consumidor, maior atenção precisa ser dada aos produtos finais da pecuária de corte. Com isso, as informações das características de carcaça e atributos intrínsecos da carne passam a ser pontos fundamentais, proporcionando dados importantes para avaliar a produtividade e qualidade de qualquer sistema de produção.

A raça do gado exerce uma influência considerável no rendimento de carcaça e na qualidade da carne, e atualmente, a carne brasileira produzida é predominante de animais Bos indicus, em torno de 80\%. Segundo Luchiari Filho (2006), as raças diferem quanto às curvas de crescimento dos tecidos e, conseqüentemente, ao menor ou maior acúmulo de gordura, ou ainda, quanto ao peso e espessura dos músculos ou cortes cárneos a um determinado peso de carcaça. Essas características são associadas aos atributos visuais e organolépticos da carne, sendo apreciadas ou discriminadas dependendo do mercado que se considera.

Para Luchiari Filho (2006), não existe raça bovina perfeita e explorar a heterose e a complementaridade entre raças, é uma ótima forma de aliar a rusticidade, fertilidade e adaptabilidade dos zebuínos com a precocidade, qualidade de carne e o acabamento de carcaça dos taurinos.

Comparados ao mesmo peso vivo, o gado indiano, principalmente a raça Nelore, tem maior rendimento que as raças taurinas em geral, por apresentar menor proporção de cabeça, patas e vísceras (Felício et al., 1988). Porém, a carne desses animais é 
considerada pouco macia, em função da maior atividade de calpastatina (Whipple et al., 1990). Norman (1982), ao trabalhar com as raças Nelore, Guzerá, Charolesa e Canchim, verificou que os zebuínos apresentaram carne menos macia que as raças Charolesa e Canchim.

Apesar disso, Restle \& Vaz (1999) salientaram, com base na escolha de raças usadas nos cruzamentos, que o rebanho Nelore brasileiro representa uma fonte genética de valor inestimável para cruzamentos, em virtude do grande número de exemplares disponíveis e também da complementaridade desta raça entre os genótipos europeus com maior potencial de crescimento, sejam raças britânicas, como a Hereford (Restle et al., 1997), sejam raças continentais, como a Charolesa (Restle et al., 1995). O Charolês é a raça européia utilizada nos trabalhos de cruzamentos para a formação do gado Canchim, sendo a única raça européia especializada para corte apresentando características de boa adaptação as condições brasileiras.

Além da escolha da raça, Restle \& Vaz (2002) observaram que, na busca da padronização da qualidade da carne, o abate dos animais deveria ocorrer com até dois anos de idade. Porém, o Brasil, nas melhores das situações, o gado Bos indicus é abatido com 24-26 meses em confinamento ou 36-42 meses em boas pastagens. Além disso, a maior parte do rebanho bovino de corte é constituído de animais zebuínos, puros ou cruzados, criados a pasto, com pouca ou nenhuma suplementação, o que leva a uma idade de abate avançada e, portanto a produção de carcaças de baixa qualidade (Andrighetto et al., 2006).

Do ponto de vista mercadológico, houve um aumento da homogeneidade na atitude dos consumidores, que criam à demanda, e direcionam o setor produtivo especialmente de produtos in natura (Hardwick, 1998). Sendo assim, os consumidores, que estão se tornando mais esclarecidos e exigentes, buscam produtos de melhor qualidade. Adicionalmente, a preocupação com os aspectos relacionados à saúde e bem estar das pessoas, também tem aumentado consideravelmente (Luchiari Filho, 2006).

Segundo Luchiari Filho (2006), no caso específico de carnes, essa demanda acontece tanto pelos atributos intrínsecos de qualidade como, maciez, sabor, quantidade de gordura, como também, pelas características voltadas para as formas de produção, processamento, comercialização, etc. Portanto, um produto que apresente apenas 
questões relacionadas à higiene, saúde e bem estar, não tem aceitação garantida caso não seja suculento, saboroso e macio.

A maciez, tem se mostrado o mais variável e mais importante componente sensorial que afeta a satisfação dos consumidores (Sanders et al., 1997; Miller et al., 2001). Em 1995, a National Beef Quality Audit americana listou a maciez como o maior problema de qualidade de carne e o segundo maior no que diz respeito à indústria. Sendo que, inadequada maciez tem um custo anual estimado entre U\$ 7,64 por animal, ou U\$ 217 milhões para a indústria de carne bovina norte-americana (Smith et al., 1995).

Já para Liu et al. (1995), as três propriedades pelas quais os consumidores julgam qualidade de carne é aparência visual, textura, e sabor. A mais importante desta, é a aparência visual, porque influencia fortemente a decisão de compra do consumidor (Kropf et al., 1986; Faustman \& Cassens, 1990a), sendo esta uma das únicas, ou muitas vezes, a única forma de avaliação da qualidade da carne pelo consumidor, no momento da compra.

A cor que é considerada uma importante característica sensorial na aparência da carne, pode não apenas valorizá-la, mas também depreciá-la (MacDougall, 1994). Além da coloração, a oxidação lipídica é outro grande fator de influência, resultante da produção de radicais livres, que podem conduzir a oxidação de pigmentos da carne e ao início de odores de ranço e sabores indesejáveis, ocasionando rejeição pelo consumidor na hora da escolha do produto cárneo (Liu et al., 1995).

Nos últimos anos, inúmeras técnicas estão sendo empregadas na indústria da carne vermelha e na produção de bovinos de corte para melhorar a qualidade da carne, visando atender um mercado consumidor cada vez mais exigente. Uma tecnologia que pode ser utilizada visando melhorar a qualidade da carne, é a suplementação de vitaminas $\mathrm{D}_{3}$ e $\mathrm{E}$, via oral, durante o arraçoamento dos animais.

O fornecimento de vitamina $\mathrm{D}_{3}$ disponibiliza cálcio suficiente para ativar as proteases dependentes de cálcio ( $\mu$ - e m-calpaínas) e acelera o processo de amaciamento da carne (Montgomery et al., 2000a; Swanek et al., 1999a), e conseqüentemente diminui o período de maturação da carne, gerando uma economia para a indústria. Já, o fornecimento de Vitamina $\mathrm{E}$, aumenta a durabilidade dos produtos cárneos, visto que é 
um potente antioxidante que evita a oxidação do lipídeo e da mioglobina (Faustman et al., 1989).

\section{Vitaminas}

Atualmente, a suplementação vitamínica, é prática de manejo comum nas dietas oferecidas aos animais em produção. Porém, as vitaminas são compostos muito sensíveis e facilmente podem ser destruídas no processamento ou na estocagem das rações, sendo que cada fonte natural apresenta uma disponibilidade diferente para a absorção animal.

Rucker \& Morris (1997) definem as vitaminas como um grupo heterogêneo de compostos orgânicos, presentes em pequenas quantidades nos alimentos naturais, essenciais para o metabolismo normal dos tecidos animais, na qual, a falta promove doenças deficitárias. Já Zeoula \& Geron (2006) as definem como substâncias orgânicas essenciais dieteticamente, distintas de proteínas, glicídios e lipídeos que são exigidas em pequenas quantidades.

Embora não participem como unidade estrutural das células ou não sejam utilizadas para o fornecimento de energia, são essenciais para a síntese de tecidos e obtenção de energia dos nutrientes, sendo fundamentais a boa saúde, crescimento, reprodução e produção animal (McDowell, 1989).

As vitaminas podem ser classificadas de acordo com propriedades químicas e físicas, sendo solúveis em solução aquosa ou solventes lipídicos (Friedrich, 1988). As solúveis em solventes lipídicos (A, D, E e K) são absorvidas e transportadas pelo processo de transporte convencional de lipídeos. Já para as solúveis em água (Complexo B e C), os coeficientes de solubilidade são os maiores fatores que ditam a facilidade de absorção (Rucker \& Morris, 1997).

A vitamina D é sintetizada via radiação ultravioleta na pele dos ruminantes, sendo dispensável sua suplementação (Zeoula \& Geron, 2006). Contudo, atenção especial deve ser dada a suplementação exógena de vitamina E, pois esta não é sintetizada pelo organismo. 


\section{Vitamina D}

Edward Mellanby, em 1921, induziu o raquitismo em cachorros pela manipulação da dieta. Ele descobriu que a doença poderia ser corrigida com óleo de fígado de bacalhau. Posteriormente, Mc Collum, em 1922, informou que o fator curativo no óleo de fígado de bacalhau não foi a vitamina $\mathrm{A}$, mas pareceu ser outra substância solúvel em gordura. Esta substância foi mais tarde identificada como vitamina D (Rucker \& Morris, 1997).

Existem duas formas principais de vitamina D significantes na medicina veterinária, o ergocalciferol (vitamina $\mathrm{D}_{2}$ ) que é derivado de esteróides de plantas e o colecalciferol (vitamina $\mathrm{D}_{3}$ ) que é derivado do precursor 7-dehidrocolesterol, encontrado somente em tecidos animais ou produtos destes (NRC, 1996). A vitamina $D_{2}$ é sintetizada por radiação ultravioleta a partir do esteróide ergosterol (presentes em vegetais, fungos e leveduras), sendo conhecida como a forma sintética, e apresenta a mesma atividade da vitamina $\mathrm{D}$ natural (vitamina $\mathrm{D}_{3}$ ). Tanto a forma sintética, como a natural, apresentam atividade biológica semelhantes para bovinos (NRC, 2001).

\subsection{Requerimento de vitamina $D$ para ruminantes}

As doses diárias de vitamina $\mathrm{D}$ recomendadas, não são atingidas através da alimentação normal, pela pequena quantidade contida nos alimentos, a não ser naqueles enriquecidos com esta vitamina. A recomendação de vitamina $\mathrm{D}$ também é complicada, devido à exposição dos animais ao sol, pois esta á ativada pela radiação ultravioleta. Bovinos expostos a luz solar ou alimentados com feno, raramente necessitam desta suplementação, pois conseguem sintetizá-la (Zeoula \& Geron, 2006).

O requerimento de vitamina D para bovinos de corte é $275 \mathrm{UI} / \mathrm{Kg}$ de matéria seca, sendo que uma unidade internacional de vitamina $D$ é definida como $0,025 \mu \mathrm{g}$ de colecalciferol $\left(\mathrm{D}_{3}\right)$ (NRC, 1996). O NRC (2001) sugere que o nível máximo de tolerância para a vitamina D é de $2.200 \mathrm{UI} / \mathrm{Kg}$ de dieta, quando animais são alimentados por longos períodos (mais de 60 dias) e 25.000UI/Kg de dieta, quando são alimentados por períodos curtos.

Millen et al. (2009) relataram que a concentração média da vitamina D recomendada pelos nutricionistas foi $82,3 \mathrm{UI} / \mathrm{Kg}$. Porém, os autores constataram que os nutricionistas brasileiros não suplementam vitaminas lipossolúveis em dietas de 
terminação, sendo que as concentrações foram abaixo do recomendado pelo NRC (1996). Os autores comentam que o limitado uso de vitaminas em confinamentos brasileiros, reflete geralmente a períodos curtos de alimentação em relação aos confinamentos norte-americanos. Além disso, o custo da suplementação também é um grande entrave para seu uso.

\subsection{Metabolismo e função da vitamina D}

No organismo, a vitamina D é necessária para absorção de cálcio e fósforo, mineralização dos ossos, mobilização do cálcio do osso e imunidade. A função principal desta vitamina é elevar os níveis de cálcio e fósforo do plasma por supersaturação, necessário para a mineralização normal dos ossos. Isto ocorre, estimulando a absorção intestinal do cálcio e fósforo, a mobilização dos ossos já formados e melhorando a reabsorção renal (Weiss, 1998; Blezinger, 2001).

O 7-deidrocolesterol (provitamina $\mathrm{D}_{3}$ ) é produzido no organismo animal a partir do metabolismo do colesterol e excretado pelas glândulas sebáceas. Na pele é transformado em colecalciferol (vitamina $\mathrm{D}_{3}$ ), por ação dos raios solares ultravioleta, com comprimento de onda 290-315nm. Dessa forma, a quantidade de colecalciferol formado depende da freqüência e da intensidade dos raios ultravioletas que alcançam o animal (Zeoula \& Geron, 2006).

Logo, o colecalciferol produzido na epiderme, é absorvido e transportado pelo sangue, onde se liga a uma $\alpha$-globulina e imediatamente torna-se disponível para $o$ metabolismo. Assim, a vitamina D atinge o fígado, e o metabólito 25-hidroxicalciferol $\left(25(\mathrm{OH}) \mathrm{D}_{3}\right)$ é formado. Essa reação é fortemente inibida pelo produto formado, prevenindo o acúmulo de níveis tóxicos (Zeoula \& Geron, 2006). O fígado é o principal local de formação do $25(\mathrm{OH}) \mathrm{D}_{3}$, porém o intestino e rim também podem produzir, só que em pequenas quantidades.

Então, o 25(OH) $\mathrm{D}_{3}$ é transportado para os rins, onde o 1,25-diidroxicolecalciferol $\left(1,25(\mathrm{OH})_{2} \mathrm{D}_{3}\right)$ é produzido. Este o principal metabólito ativo da vitamina $\mathrm{D}$ e apresenta cinco vezes mais atividade que o $25(\mathrm{OH}) \mathrm{D}_{3}$ (NRC, 1996), sendo considerada a forma hormonal da vitamina $\mathrm{D}$, já que é produzida em um local (rim) e atua em outro (ossos).

$\mathrm{O}\left(1,25(\mathrm{OH})_{2} \mathrm{D}_{3}\right)$ é transportado para a mucosa intestinal, osso e túbulos renais, onde estará envolvido no metabolismo do cálcio e fósforo. Altos teores de cálcio 
reduzem a formação de $1,25(\mathrm{OH})_{2} \mathrm{D}_{3}$ e baixos teores, estimulam. Contudo, a falta de cálcio determina a secreção do hormônio da paratireóide que, por sua vez, promove a conversão enzimática de $25(\mathrm{OH}) \mathrm{D}_{3}$ em $1,25(\mathrm{OH})_{2} \mathrm{D}_{3}$ e estimula diretamente a absorção de cálcio para a formação dos ossos (Zeoula \& Geron, 2006).

É importante observar que, o efeito da suplementação de vitamina D visa à chegada desta intacta ao intestino, para ser absorvida e participar do metabolismo. Porém, Bellet et al. (2000), demonstraram o desaparecimento de 70\% de vitamina D no rúmen a partir de incubações por 24 horas com líquido ruminal, obtido de novilhos alimentados com forragem. Concluiu-se em seu trabalho, que a degradação foi devido à atividade dos microorganismos ruminais.

\subsection{Vitamina D e Qualidade de carne}

Dentre as características de qualidade da carne bovina, a maciez assume posição de destaque sendo considerada a característica sensorial de maior influência na aceitação da carne pelos consumidores (Paz \& Luchiari Filho, 2000). Em meio aos fatores que influenciam na maciez da carne, destacam-se o estresse, a genética (raça), sexo, idade de abate, alimentação, e tratamentos pós-morte como o resfriamento e a estimulação elétrica das carcaças, a maturação e o método de cocção da carne (Felício, 1997)

Historicamente, a carne dos zebuínos (Bos indicus) é identificada como menos macia, porque esses animais são criados a pasto e abatidos mais velhos. A menor maciez da carne, dos zebuínos também é justificada pela idade de abate e o número de ligações cruzadas termoestáveis do colágeno dos músculos, favorecendo o endurecimento da carne (Felício, 1997).

Wheeler et al. (1990) demonstraram que outro fator estaria relacionado com a maciez da carne. Os zebuínos apresentam maiores concentrações de calpastatina, inibidora das proteases dependentes de cálcio ( $\mu$-e m-calpaínas), responsável pela maciez da carne (Montgomery et al., 2000a). Deste modo, o uso da vitamina $\mathrm{D}_{3}$ no amaciamento da carne disponibilizaria cálcio suficiente para ativar as proteases dependentes de cálcio ( $\mu$-e m-calpainas) e acelerar o processo de amaciamento da carne (Montgomery et al., 2000a; Swanek et al., 1999). 
Swanek et al. (1999) utilizaram 7,5 x $10^{6}$ UI de vitamina $\mathrm{D}_{3}$ por 10 dias antes do abate e observaram que a suplementação de vitamina $D_{3}$ reduziu a força de cisalhamento no músculo Longissimus em novilhos e aumentou a concentração de cálcio do plasma e do Longissimus em comparação ao grupo controle. A concentração de cálcio plasmático encontrada foi de 213,0 mg/L, para animais suplementados, e $142,0 \mathrm{mg} / \mathrm{L}$ para o grupo controle.

Montgomery et al. (2002), suplementaram novilhos com doses diárias de 0,5; 1,0; 2,5; 5,0 e 7,5 x $10^{6} \mathrm{UI} /$ animal de vitamina $\mathrm{D}$ e verificaram que todas as doses foram efetivas para aumentar o cálcio plasmático em relação ao controle.

Segundo Pedreira et al. (2003), o fornecimento de Vitamina D aumenta em 30 a $40 \%$ a concentração de cálcio muscular, sendo este nível de cálcio suficiente para ativar o sistema de amaciamento das proteases cálcio-dependentes (calpaínas), resultando na redução da dureza da carne em até $50 \%$.

Em diferentes estudos, Karges et al. (2001) e Foote et al. (2004), verificaram que ao suplementar novilhos com vitamina $\mathrm{D}_{3}$, aumenta-se a concentração de cálcio plasmático em relação ao grupo controle, e melhora a maciez da carne, demonstrando que a vitamina $\mathrm{D}_{3}$ disponibiliza maior quantidade de cálcio para agir no sistema de amaciamento da carne.

Montgomery et al. (2002), suplementaram novilhos com 7,5 x $10^{6} \mathrm{UI} /$ animal de vitamina $\mathrm{D}_{3}$, durante 9 dias antes do abate e avaliaram a concentração de vitamina $\mathrm{D}$ no músculo. Os valores encontrados foram de $65,9 \mathrm{ng} / \mathrm{g}$ para os animais suplementados, e 9,5 ng/g para o controle (sem suplementação). Já Foote et al. (2004), suplementaram novilhos com 5,0 × $10^{6} \mathrm{UI} /$ animal de vitamina $\mathrm{D}_{3}$, durante 9 dias antes do abate, e encontraram a concentração de 38,06 ng/g para os animais suplementados e 1,10 ng/g para o controle (sem suplementação).

Montgomery et al. (2004), suplementaram novilhos Bos taurus (predominantemente Angus e Hereford), Bos taurus (predominantemente Charolês e Limousin) e Bos indicus, e informaram que o tratamento com vitamina D reduz a força de cisalhamento dos grupos genéticos igualmente.

Adicionalmente, a maturação é uma alternativa tecnológica para aumentar a maciez da carne. Consiste em manter a carne após o processo de rigor-mortis sob refrigeração (temperatura em torno de $0^{\circ} \mathrm{C}$ ) por um período variável, após o abate. De 
acordo com Felício (1997), a maturação pode melhorar em cerca de 25\% a maciez da carne, mas sua eficácia é bem menor em carcaças de bovinos de quatro ou mais anos bem como naquelas que sofreram um rigoroso "encurtamento pelo frio".

O íon cálcio é um agente regulador do sistema contrátil, além de apresentar um papel importante no fenômeno de amaciamento da carne durante maturação pós-morte, sendo que sua concentração aumenta gradualmente durante a maturação pós-morte (Pedreira et al., 2003).

Durante a maturação, a carne sofre a ação das enzimas calpaínas e catepsinas que são enzimas cálcio-dependentes (Andrighetto et al., 2006). Segundo Koohmaraie et al. (1994), essas enzimas promovem uma série de alterações no tecido muscular, causando uma diminuição da rigidez e aumento gradativo da maciez da carne. Para Pardi et al. (1995), além do amaciamento, o processo de maturação exerce importante influência em outras propriedades organolépticas da carne, como o sabor, afetando acentuadamente sua palatabilidade.

Para verificar a influência do tempo de maturação, estudos foram realizados averiguando a influência da raça no tempo de maturação. Segundo Bianchini et al. (2007) animais Bos indicus, necessitam de um período mínimo de 7 dias de maturação para apresentar carne macia. Adicionalmente, para bovinos abatidos até 14 meses de idade, 7 dias já seriam suficientes para apresentar carne macia.

A carne de bovinos, maturada por 14 dias, resultou em maior proteólise comparada ao do grupo controle, quando bovinos foram suplementados diariamente com 5,0 $010^{6} \mathrm{UI}$ de vitamina $\mathrm{D}_{3}$, por 9 dias antes do abate. De acordo com os autores, o uso de suplementação dietética de vitamina $\mathrm{D}_{3}$ diária, melhora a maciez de bifes maturados por 14 dias (Montgomery et al., 2000a).

Swanek et al. (1999) suplementaram novilhos diariamente com 7,5 x $10^{6}$ UI/animal de vitamina $\mathrm{D}_{3}$, por 10 dias antes do abate e observaram que a suplementação diminui a força de cisalhamento nos cortes maturados por 7 e 14 dias comparados ao grupo controle, sem adição de vitamina D.

Montgomery et al. (2002), suplementaram novilhos com 7,5 x $10^{6} \mathrm{UI} /$ animal de vitamina $\mathrm{D}_{3}$, durante 9 dias antes do abate, e observaram redução na maciez com 7 dias de maturação, comparado ao controle, mas não por 10, 14 e 21 dias. Os autores concluíram que o tratamento com vitamina $\mathrm{D}_{3}$ pode ser efetivo para melhorar a maciez 
quando bovinos tendem a apresentar carne mais dura, porém pode não ter nenhum impacto em bovinos que produzem carne macia. Em função destes resultados, a suplementação de vitamina $\mathrm{D}_{3}$ seria uma alternativa viável para tentar reduzir o período de maturação.

\section{Vitamina $\mathbf{E}$}

Como citado anteriormente, a vitamina E encontra-se na classe de vitaminas lipossolúveis e tem sido reconhecida como um nutriente essencial para o crescimento e sanidade de todas as espécies animais, inclusive bovinos. Seus efeitos abrangem diversos aspectos do metabolismo animal, como biossíntese de prostaglandinas, resistência a doenças e principalmente ação antioxidante em sistemas biológicos (Liu et al. 1995).

O corpo não produz vitamina $\mathrm{E}$, e ela pode ser encontrada em óleos de plantas (folhas e partes verdes) sendo que a fonte dietética para animais são óleos vegetais, sementes e cereais (Rucker \& Morris, 1997). Os vários compostos existentes nas plantas com atividade biológica em vitamina $E$, são derivados de tocoferóis, sendo o d- $\alpha$ tocoferol, all-rac- $\alpha$-tocoferol, acetato $d$ - $\alpha$-tocoferil, e acetato all rac- $\alpha$-tocoferil, onde "d" designa a vitamina que ocorre naturalmente e "all-rac" significa a mistura racêmica de vitaminas, resultante de sínteses químicas (Liu et al., 1995).

Várias bioanálises animais revelaram que a forma ativa da vitamina E é o d- $\alpha-$ tocoferol (McDowell, 1989), também chamado de RRR- $\alpha$-tocoferol e apresenta atividade em vitamina E de 1,49 UI/mg (Zeoula \& Geron, 2006). Sendo que, 0,67 mg de RRR- $\alpha$-tocoferol, representam uma unidade internacional de vitamina $E$ (NRC, 1996).

O $\alpha$-tocoferol é localizado entre a membrana celular e parece ter como função principal a quebra da cadeia antioxidante do sistema biológico (Burton et al., 1983). A forma de acetato $\alpha$-tocoferol, não ocorre naturalmente, porém é a forma utilizada nas rações de animais e evita que o tocoferol seja destruído na dieta ou quando ingerido. Isto ocorre, porque os tocoferóis puros são facilmente oxidáveis, entretanto a sua esterificação com acetato forma um produto mais relativamente estável ao oxigênio atmosférico (Zeoula \& Geron, 2006). 


\subsection{Requerimento de vitamina $\mathbf{E}$ em ruminantes}

Segundo o NRC (1996), é arriscada uma recomendação precisa da vitamina E. A determinação da exigência de vitamina E é complicada, devido a sua inter-relação com outros componentes da dieta, como antioxidantes, aminoácidos sulforados e selênio. Além disso, o requerimento de vitamina $\mathrm{E}$, pode ser alterado em função do consumo de altas concentrações dietéticas de ácidos graxos poliinsaturados.

O NRC (1996) estabeleceu o requerimento de vitamina E para bovinos jovens entre 15 e $60 \mathrm{UI} / \mathrm{Kg}$ de MS. Já para bovinos em crescimento e terminação, o requerimento é de 50 a $100 \mathrm{UI} /$ dia (Hutcheson \& Cole, 1985). Segundo Liu et al. (1995), o consumo de pequenas doses de 64 UI de vitamina E diariamente poderiam satisfazer as exigências de bovinos em terminação.

Millen et al. (2009), relataram que a concentração média da vitamina E recomendada pelos nutricionistas foi $10,5 \mathrm{UI} / \mathrm{Kg}$. Porém neste trabalho, os autores constataram que os nutricionistas brasileiros não suplementam vitaminas lipossolúveis em dietas de terminação, sendo que as concentrações foram abaixo do recomendado pelo NRC (1996). Em adição, um maior uso de volumoso secos em dietas de terminação, presumidamente teria como resultado maiores concentrações basais de precursores de vitamina $\mathrm{E}$, o que não aconteceria provavelmente no caso dos confinamentos norte-americanos, onde o grão é o principal componente da dieta.

\subsection{Metabolismo e função da vitamina $E$}

A vitamina E não apresenta toxidez em virtude de sua baixa absorção, que está relacionada à digestão da gordura e é facilitada pela bile e lípase pancreática. Após a hidrólise da forma éster da vitamina $\mathrm{E}$ na parede do intestino, a forma álcool (forma livre) é absorvida e transportada, via linfa, para a circulação geral. No plasma, a vitamina E liga-se principalmente a uma lipoproteína da fração globulina (Zeoula \& Geron, 2006). Esta por sua vez, é transportada pela lipoproteína até o local de armazenamento.

Ainda há muitas contradições em relação aos principais locais de armazenamento de vitamina E. Segundo o NRC (1996), ela pode ser estocada em muitos tecidos, mas principalmente no fígado e tecido adiposo. Machlin (1984) considera o músculo, além 
do fígado e tecido adiposo, como os principais depósitos armazenadores de vitamina $\mathrm{E}$, presumidamente baseado em suas massas e habilidade para acumular a vitamina. Para Zeoula \& Geron (2006), o tecido adiposo parece ser capaz de armazenar quantidade ilimitada de vitamina E, porém geralmente não é armazenada em grande quantidade no organismo e seu estoque pode ser esgotado rapidamente pelos ácidos graxos poliinsaturados dos tecidos. Já para Faustman et al. (1989), o fígado e glândula adrenal, inclui as maiores concentrações de tocoferóis, e músculo e tecido adiposo, as menores.

Segundo Faustman et al. (1989), a vitamina E apresenta seu efeito máximo dentro de biomembranas, agindo principalmente, como um potente antioxidante inter e intracelular e na formação de componentes estruturais de membranas biológicas, além de retirar radicais livres do sistema imunológico e melhorar a resistência a doenças (McCay \& King, 1980). Esses radicais livres são neutralizados pelo $\alpha$-tocoferol através da oxidação lipídica propagada entre ácidos graxos altamente insaturados em células e membranas celulares (Machlin, 1984). Outras funções, como mantença estrutural e funcional do músculo esquelético, cardíaco, liso e sistema vascular periférico, são apresentadas (NRC, 1996).

É importante ressaltar, que o efeito da suplementação visa à chegada da vitamina E intacta no intestino, onde ela possa ser absorvida para participar do metabolismo. Leedle et al. (1993) e Weiss et al. (1995) realizaram trabalhos de fermentação in vitro que indicaram que a vitamina E não havia sido destruída, demonstrando que o metabolismo ruminal da vitamina E parece ser mínimo (Zeoula \& Geron, 2006). Ledlle et al. (1993) afirmaram que isso ocorre em função desta possuir uma dupla ligação onde incide o anel aromático, conferindo-lhe uma maior estabilidade. Porém, Bellet et al. (2000) sugeriram que a vitamina $\mathrm{E}$ era parcialmente degradada pela microflora ruminal e particularmente pelas bactérias amilolíticas.

\subsection{Vitamina E e Qualidade de carne}

A qualidade de carne atualmente é julgada por uma infinidade de variáveis, como por exemplo, aparência visual (cor e textura) e sabor. Sendo que a aparência visual é o primeiro fator usado pelos consumidores para julgar uma carne de qualidade (Liu et al., 1995). Para Montgomery et al., (2001), a deterioração na coloração é causada pela 
oxidação do pigmento presente na carne e isso reflete na preferência dos consumidores, provocando rejeição na hora da escolha do produto cárneo.

Os tecidos musculares contêm vários compostos pigmentados, sendo presentes em maiores quantidades, a mioglobina e a hemoglobina, que são proteínas do tecido muscular e sangue, e que reversivelmente se ligam com o oxigênio (Fox, 1987). A quantidade de mioglobina varia de acordo com a espécie, sexo, idade, localização anatômica do músculo, atividade física, pelo tipo de fibra muscular bem como pelo nível de sangria do animal no abate (Cornforth, 1994). Em tecidos profundamente coloridos tais como os que podem ser encontrados em bovino adulto, a mioglobina pode representar $90 \%$ ou mais do pigmento total (Warris \& Rhodes, 1977).

O estado químico da mioglobina depende da valência do íon ferro localizado no interior do heme (anel de porfirina) (Felício, 1999). Na presença de oxigênio, a mioglobina $(\mathrm{Mb})$ se transforma em oximioglobina $(\mathrm{OxiMb})$, pois o íon $\mathrm{Fe}^{+2}$ se liga a molécula de oxigênio. Isso geralmente ocorre em embalagem permeável aos gases, ou ainda nas atmosferas controladas. Por sua vez, a carne adquire uma coloração vermelhocereja, de maior luminosidade, ou seja, mais brilhante, e carnes com essa aparência, geralmente, são preferidas pelos consumidores (Comforth, 1994).

Quando o íon ferro se encontra no estado reduzido (ferroso, $\mathrm{Fe}^{+2}$ ), ele pode se ligar a uma molécula de água ou de oxigênio molecular. $\mathrm{Na}$ ausência de oxigênio molecular, o íon $\mathrm{Fe}^{+2}$ combina-se com a água, a mioglobina torna-se desoximioglobina (DesoxMb) e adquire uma coloração vermelho-escura, de baixa luminosidade. Este processo, normalmente ocorre no interior das peças ou nas carnes a vácuo, decorridas 8 a 12 horas do fechamento da embalagem (Felício, 1999).

Por outro lado, quando o íon ferro do heme se oxida, ou seja, passa do estado ferroso $\left(\mathrm{Fe}^{2+}\right)$ para o estado férrico $\left(\mathrm{Fe}^{+3}\right)$, sob baixa tensão de oxigênio, a mioglobina transforma-se em metamioglobina $(\mathrm{MetaMb})$ de coloração marrom, indesejável do ponto de vista do consumidor (Morrissey et al., 1994). Este efeito, geralmente é verificado em embalagem semipermeável e nas situações em que, nem a ausência, nem a presença de oxigênio são totais.

- Presença de $\mathrm{O}_{2}=\mathrm{Fe}^{(+2)}+\mathrm{O}_{2}=$ OxiMb

- Ausência de $\mathrm{O}_{2}=\mathrm{Fe}^{(+2)}+\mathrm{H}_{2} \mathrm{O}=$ DesoxiMb 
- $\mathrm{Fe}^{(+2)}=\mathrm{Fe}^{(+3)}=$ MetaMb

Segundo Lanari et al. (1989), o ciclo da cor da carne é reversível e dinâmico, havendo uma constante interconversão entre DesoxMb e OxiMb, e MetaMb. Sendo assim, a oxigenação da mioglobina pode ser interpretada como a primeira ordem da reação reversível. Contudo, a metamioglobina, quando formada, ainda pode ser revertida a desoximioglobina e, em seguida, oxigenada. No caso da metamioglobina formar-se por exposição prolongada à luz e ao oxigênio, a redução de $\mathrm{Fe}^{+3} \mathrm{a} \mathrm{Fe}^{+2}$ já não será possível (Felício, 1999).
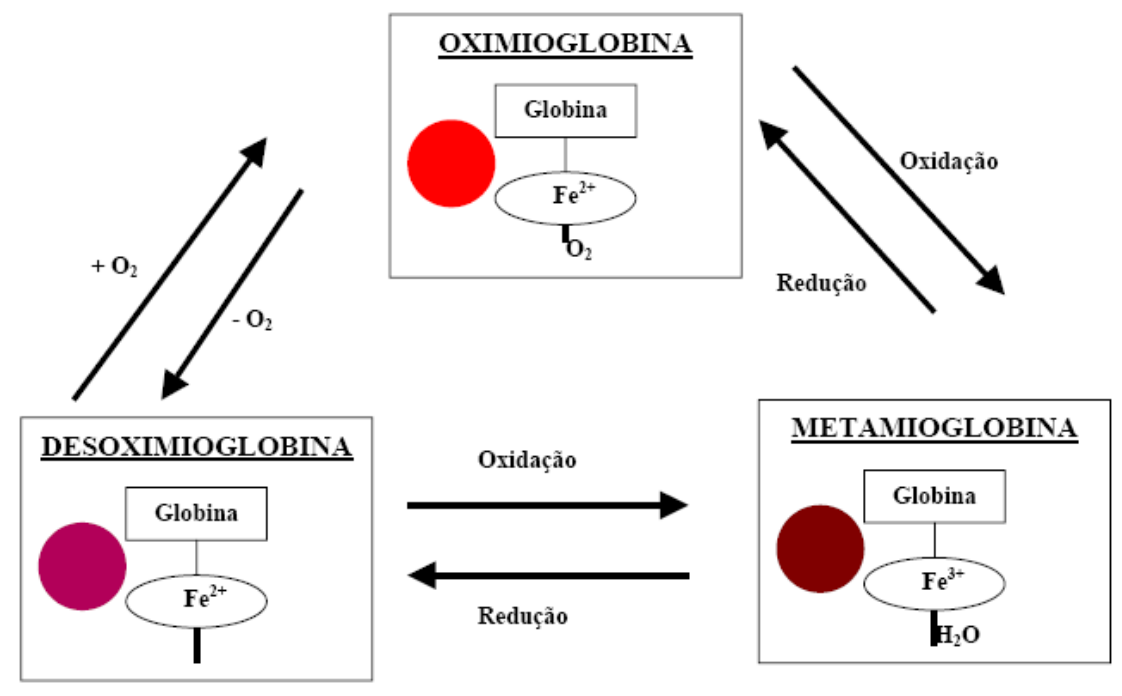

Figura 1. Relação entre o estado da mioglobina e a cor da carne.

A estabilidade da oximioglobina é melhorada com o aumento nas concentrações de $\alpha$-tocoferol no músculo (Chan et al., 1996). A vitamina E promove uma proteção das membranas biológicas e pigmentos musculares de danos oxidativos, promovendo a estabilidade da coloração e conseqüentemente, aumenta a vida de prateleira, por meio do acúmulo de $\alpha$-tocoferol no músculo (Arnold et al., 1993).

A suplementação dietética de vitamina $\mathrm{E}$ tem resultado em um aumento na extensão da durabilidade da carne durante a exposição em 1,6 a 5 dias, sem comprometer a qualidade microbiológica. A extensão da coloração durante a vida de prateleira, depende da dose e duração da suplementação, tipo muscular e período de maturação (Gray et al., 1996; Liu et al., 1995), além do nível de iluminação, 
temperatura de armazenamento, métodos de embalagem (Kropf, 1982; Lanari et al., 1989; Liu et al., 1995).

Em um estudo realizado para verificar a preferência dos consumidores pela carne de animais suplementados com vitamina E. Os resultados indicaram que, 91\% dos participantes preferiram carne de bovinos suplementados, ao invés da carne de animais não suplementados, em função da vitamina $\mathrm{E}$ ter promovido melhor estabilidade da coloração da carne. Neste estudo, foi detectado que 58\% dos participantes identificaram a cor do músculo como o mais importante fator na seleção de produtos cárneos (Sanders et al., 1997).

Arnold et al. (1992a) ao suplementar novilhos holandeses com vitamina E, verificaram que a suplementação adicional de 300 UI por 266 dias, 1140 UI por 67 dias e 1200 UI por 38 dias, foi efetiva para estender a coloração do músculo Longissimus em 2,5; 2,5 e 4,8 dias, respectivamente, quando em exposição sob condições simuladas de varejo, embaladas em filme permeável ao oxigênio, com temperatura entre 2,5 a $5^{\circ} \mathrm{C}$, sob iluminação de 1900 a 2600 1x. Neste mesmo trabalho, Arnold et al. (1992a), avaliaram a concentração de $\alpha$-tocoferol no músculo de novilhos suplementados com 1140 UI de vitamina E por 67 dias e 1200 UI de vitamina E por 38 dias. Para os animais suplementados com $1140 \mathrm{UI}$, o controle e os suplementados continham 2,0 e $6,2 \mu \mathrm{g} / \mathrm{g}$ de músculo, respectivamente. Para os animais suplementados com 1200 UI, o controle e os suplementados continham 2,2 e 3,5 $\mu \mathrm{g} / \mathrm{g}$ de músculo, respectivamente. Os autores sugerem que a dosagem de 1200 UI por 38 dias, foi suficiente para melhorar a estabilidade da cor.

Arnold et al. (1993b) e Faustman et al. (1989), relataram que a concentração ideal de $\alpha$-tocoferol no músculo de novilhos, para melhorar a estabilidade lipídica e conseqüentemente a estabilidade da coloração, é de 3,0 a 3,5 $\mu \mathrm{g} / \mathrm{g}$ de músculo. Arnold et al. (1993b), sugeriram que a concentração de $\alpha$-tocoferol no músculo poderia ser elevada de $1,4 \mu \mathrm{g} / \mathrm{g}$ para a concentração ideal de $3,5 \mu \mathrm{g} / \mathrm{g}$ com a dose de $1.300 \mathrm{UI} / \mathrm{d}$ por um período de 44 dias.

Yang et al. (2002) suplementaram novilhos cruzados Hereford com as doses diárias de $2500 \mathrm{UI} /$ animal de acetato de $\alpha$-tocoferol, por um período de 132 dias. Avaliou-se a coloração da carne pelo método CIELAB (L*, a*, b*) de amostras de Longissimus, embaladas em filme permeável ao oxigênio e estocadas por 7 dias a $4^{\circ} \mathrm{C}$. 
Os resultados demonstraram que a suplementação não melhorou a estabilidade da cor de carnes frescas expostas por sete dias, em animais alimentados com dietas ricas em grãos.

A maioria dos trabalhos presentes na literatura, não consideram o valor de $\mathrm{L}^{*} \mathrm{e} \mathrm{b}$ (O’Grady et al., 1998; Gatellier et al., 2001; Eikelenboom et al., 2000; Stubbs et al, 2002; citados por Lage, 2004), ou não encontraram diferença entre carne oriunda de animais suplementados ou não (Chan et al., 1996, 1998; Mitsumoto et al., 1998; Houben et al., 1998, 2000; citados por Lage, 2004). Eikelenboom et al. (2000) não encontraram nenhum efeito da vitamina $E$ sobre os valores de $a^{*}$, em carne fresca. Contudo, Zerby et al. (1999), observaram que o corte do contrafilé de bovinos que receberam vitamina $\mathrm{E}$, apresentaram maiores valores de $\mathrm{a}^{*}$, em relação ao grupo controle.

Além da oxidação do pigmento, a oxidação lipídica é um dos principais fatores limitantes de qualidade e aceitabilidade pelos consumidores. Este processo resulta na descoloração, desenvolvimento de odores e sabores finais e produção de componentes tóxicos (Gray et al., 1996), podendo ocorrer devido ao alto consumo de lipídeos oxidados ou ácidos graxos poliinsaturados, ou pelo consumo de nutrientes envolvidos no sistema de defesa antioxidante (Morrissey et al., 1998).

A propensão de produtos cárneos sofrer oxidação depende de vários fatores, incluindo eventos pré-abate como estresse e eventos pós-abate como $\mathrm{pH}$, temperatura da carcaça, encurtamento pelo frio, e técnicas como estimulação elétrica (Bucley et al., 1995). Além disso, a ruptura da integridade das membranas musculares pela desossa, moagem e cozimento alteram a compartimentalização celular, proporcionando uma menor estabilidade lipídica.

A oxidação é iniciada na membrana, nas frações dos fosfolipídios intracelulares (Asghar et al., 1990). Segundo Morrissey et al. (1998), a oxidação lipídica ocorre em três fases. A primeira é considerada a fase de produção espécies reativas ao oxigênio e mecanismos de defesa antioxidantes, que ocorre no animal vivo. A segunda fase, de danos oxidativos, ocorre no período imediatamente após o abate, enquanto que a terceira fase ocorre durante o manejo, processamento, armazenamento e cozimento.

$\mathrm{Na}$ fase pós-abate, é altamente improvável que o sistema defensivo antioxidante (superóxido dismutase, glutationa peroxidase, ceruloplasmina e transferrina) disponível 
na célula no animal vivo, ainda funcione, por causa das alterações quantitativas em vários metabólitos e propriedades físicas (Morrissey et al., 1994). Em muitos casos, o sistema defensivo antioxidante pode ser enfraquecido pela deficiência da dieta em retinol, vitaminas $\mathrm{C}$ e E, carotenóides e elementos traços como, $\mathrm{Cu}, \mathrm{Mn}$ e Se (Buckley et al., 1995).

A presença ou ausência de vitamina E no tecido animal, influencia a estabilidade de lipídeos presentes na carne durante o armazenamento. Ela atua como um potente antioxidante lipossolúvel nas células da membrana, sendo capaz de extinguir os radicais livres e assim proteger fosfolipídios e colesterol contra a oxidação (Gray et al., 1996).

Estudos indicam que o suplemento dietético da vitamina E para gado de corte, aumenta a concentração do $\alpha$-tocoferol no músculo e em suas frações subcelulares membranosas. A concentração aumentada do $\alpha$-tocoferol no tecido protegeu, não somente os lipídios da membrana, mas também a mioglobina da oxidação. Isto resultou no atraso na descoloração da carne e na supressão da rancificação lipídica (Liu et al., 1995).

Este papel da vitamina $\mathrm{E}$ fornece uma avaliação de como a oxidação lipídica afeta a qualidade e a durabilidade da carne e de produtos cárneos, e como a durabilidade da carne, pode ser estendida por meio da suplementação acima dos níveis requeridos (Gray et al,1996).

Yang et al. (2002) e Arnold et al. (1993a) relataram que a suplementação de bovinos com as doses diárias entre 500 e 3600 UI/animal foram efetivas para inibir a oxidação lipídica da carne durante a exposição sob condições simuladas de varejo.

Liu et al. (1995) demonstraram que a concentração de 3,5 $\mu \mathrm{g} / \mathrm{g}$ de $\alpha$-tocoferol no músculo, foi suficiente para suprimir a formação de metamioglobina e a oxidação de carnes fresca. Já Mitsumoto et al. (1998), encontraram diferença na concentração de $\alpha$ tocoferol em amostras de carnes estocadas durante 6 dias a $1^{\circ} \mathrm{C}$ e embaladas a vácuo, com valores de 2,6 $\mu \mathrm{g} / \mathrm{g}$ para a carne dos animais suplementados e 1,7 $\mu \mathrm{g} / \mathrm{g}$ para o controle, respectivamente.

Dusfrane et al. (2000), encontraram uma maior concentração de $\alpha$-tocoferol para o músculo de animais suplementados $(1,9 \mu \mathrm{g} / \mathrm{g})$, em relação ao controle $(0,9 \mu \mathrm{g} / \mathrm{g})$, armazenada a $4^{\circ} \mathrm{C}$ por até 14 dias, com iluminação controlada, demonstrando que a 
suplementação permitiu maior acúmulo de $\alpha$-tocoferol no músculo, e conseqüentemente, menor oxidação lipídica.

\subsection{Perfil de ácidos graxos}

Por outro lado, o estudo do perfil de ácidos graxos que compõe a gordura presente na carne é de extrema importância (Souza, 2005). Segundo Morrissey et al. (1998), embora os lipídios insaturados, sejam desejáveis na alimentação humana, com o aumento do grau de insaturação dos lipídios aumenta a sua predisposição à oxidação, o que aumenta a dificuldade de conservação das carnes.

Wood et al. (2003), relataram que o crescente interesse no desenvolvimento de estratégias de manipulação da composição de ácidos graxos da carne bovina está relacionado à necessidade de se produzir carne mais saudável para reduzir a associação do consumo de carne bovina à ocorrência de algumas doenças.

Segundo Nunes (1998), a peroxidação (autoxidação) dos lipídios é uma reação em cadeia desencadeada por um radical ativo $(* \mathrm{R})$ formado pela retirada ou entrada de um radical RH em um ácido graxo insaturado, formado em qualquer outro local. Esse radical $* \mathrm{R}$ reage com o oxigênio molecular para formar um radical peróxido ( $\left.\mathrm{ROO}^{*}\right)$, que ataca qualquer outra molécula lipídica poliinsaturada; no processo ocorre a formação de um novo radical *R.

Esse processo propagativo continua, consumindo grande quantidade de ácidos graxos poliinsaturados e produzindo uma quantidade correspondente de hidroperóxidos. A reação só é paralisada quando o radical ROO* encontrar outro ROO*, formando um produto inativo. Essa reação pode ser interrompida por antioxidantes, como por exemplo, a vitamina $E$ ( $\alpha$-tocoferol), que inibam a formação dos radicais iniciais e assim, impeçam a propagação da reação, reagindo rapidamente com os peróxidos (ROO*) e evitando que eles reajam com os ácidos graxos poliinsaturados.

Trabalhos de Cook (2001) e Varela et al. (2004), demonstraram que ácidos graxos saturados de cadeia longa são responsáveis por vários processos metabólicos maléficos à saúde humana, como por exemplo, os problemas cardíacos. Por outro lado, os ácidos graxos insaturados de cadeia longa surgem como participantes de processos benéficos a saúde humana. 
French et al. (2000), afirmaram que a gordura da carne dos ruminantes apresenta maior concentração de ácidos graxos saturados e menor relação poliinsaturados:saturados em comparação à da carne de não-ruminantes, principalmente em virtude do processo de biohidrogenação dos ácidos graxos não-saturados no rúmen pela ação dos microrganismos. Entretanto, bovinos mantidos em diferentes sistemas de produção e compostos por diferentes raças, ou até mesmo raças puras, apresentam distintos padrão de deposição de tecido adiposo e perfil de ácidos graxos na carne, podendo afetar diretamente a qualidade da carne que está sendo produzida (Cucki, 2006). Além disso, vários fatores podem afetar a composição de ácidos graxos da carne de bovinos, entre eles a raça, a idade do animal e o tipo de dieta (Enser et al., 1998).

Segundo Bauchart (1993), o sítio de absorção dos ácidos graxos de cadeia longa é o intestino delgado, onde chegam os ácidos graxos da dieta e os lipídios sintetizados pelas bactérias ruminais, os quais são constituídos em sua maioria de ácido esteárico (C18:0) e palmítico (C16:0) e apenas de 15 a 20\% de ácidos graxos monoinsaturados (MUFA), sendo que em bovinos, a absorção intestinal média dos ácidos graxos insaturados é maior que os saturados (92 vs. 80\%). Após a absorção, os ácidos graxos são reesterificados ao glicerol e transportados por lipoproteínas através da linfa e corrente sanguínea até os tecidos periféricos para serem depositados na membrana celular (fosfolipídios), citoplasma dos adipócitos (triglicerídeos) ou oxidados para a produção de energia.

Os ácidos graxos saturados mirístico (C14:0) e palmítico (C16:0), são considerados hipercolesterolemicos (Hegsted et al., 1965), enquanto os monoinsaturados (MUFA) e polinsaturados (PUFA), são considerados efetivos na diminuição da concentração de colesterol e lipoproteínas de baixa densidade (LDL) no sangue humano (Matson et al., 1985), com exceção dos isômeros trans dos MUFA, especialmente C18:1 que tem sido associado ao alto risco de doenças cardiovasculares (Williams, 2000).

Logo, a concentração dos ácidos graxos polinsaturados linoléico (C18:2) e linolênico (C18:3) é maior nos músculos que na gordura subcutânea (Christie, 1981) e se eleva marcadamente quando os bovinos são alimentados com dietas ricas em cereais e sementes ou óleos com alto teor destes ácidos graxos (Marmer et al., 1984). Porém, não têm havido muito interesse no aumento da concentração destes ácidos graxos na 
carcaça devido seus efeitos adversos sobre o sabor, coloração e estabilidade da carne em relação a oxidação dos lipídios (Morrissey et al., 1998).

Contudo, atualmente há crescente interesse no aumento da concentração de alguns isômeros específicos do ácido linoléico, com a denominação geral de ácido linoléico conjugado (CLA). O ácido linoléico é um ácido graxo insaturado de 18 carbonos com 2 duplas ligações, na posição 9 e 12, ambas na configuração espacial cis (do mesmo lado). Porém, o isômero predominante é o cis-9, trans-11, que representa de 80 a $90 \%$ do CLA contido nos alimentos (Pariza et al., 2001).

O fornecimento apenas de C18:2 trans-10, cis-12, o isômero que leva a uma menor síntese de gordura, resultou em menor eficiência alimentar em camundongos (Pariza et al., 2001). O fornecimento dos dois isômeros (cis-9, trans-11 e trans-10, cis12) resultou em eficiência $33 \%$ maior que os animais do grupo controle que não consumiram CLA, demonstrando haver ação sinérgica entre estes isômeros (Pariza et al., 2001).

A concentração média de CLA nos produtos de bovinos (carne e leite) é de 3 a 7 $\mathrm{mg} / \mathrm{g}$ de lipídios (Chin et al., 1992) podendo variar em função de vários fatores, entre os quais, a fonte e quantidade de lipídios na dieta (Griinari et al., 2000), a proporção de forragens ou concentrado:volumoso na dieta (French et al., 2000) e raça dos animais (Lawless et al., 1999).

Descalzo et al. (2005) suplementaram novilhos cruzados com 500 UI de vitamina E por dia, para avaliar a qualidade da carne e a estabilidade oxidativa, e verificaram que não houve efeito da suplementação na composição dos ácidos graxos. Yang et al. (2002), suplementaram novilhos cruzados Hereford com 2500 UI de vitamina E por dia e não encontraram efeito da suplementação na composição dos ácidos graxos de carne e lipídeos totais, durante 7 dias de armazenamento.

A presente dissertação objetivou avaliar a suplementação de vitaminas D e E no desempenho, características de carcaça e na qualidade de carne de bovinos jovens confinados. O Capítulo 2, intitulado "DESEMPENHO, CARACTERÍSTICAS DE CARCAÇA E ATRIBUTOS DA CARNE DE BOVINOS JOVENS CONFINADOS SUPLEMENTADOS COM VITAMINAS D E E" está redigido de acordo com as normas da Revista Brasileira de Zootecnia. 


\section{Referência Bibliográfica}

ANDRIGUETTO, C. et al. Maturação da carne bovina. Revista Eletrônica de Veterinária, v. 7, n. 6, 2006.

ARNOLD, R. N. et al. Effect of long- or short-term feeding of a-tocopheryl acetate to Holstein and crossbred beef steers on performance, carcass characteristics, and beef color stability. Journal of Animal Science, v. 70, p. 3055, 1992.

ARNOLD, R.N. et al. Dietary $\alpha$-tocopheryl acetate enhances beef quality in Holstein and beef breed steers. Journal Food Science, v. 58, p.28, 1993.

ARNOLD, R.N. et al. Tissue equilibration and subcellular distribution of vitamin $\mathrm{E}$ relative to myoglobin and lipid oxidation in displayed beef. Journal Food Science, v. 71, p. 105,1993 b.

ASGHAR, A. et al. Effects of dietary oils and a-tocopherol supplementationon membranal lipid oxidation in broiler meat. Journal Food Science, v. 55, p. 46, 1990. ASSOCIAÇÃO BRASILEIRA DAS INDÚSTRIAS EXPORTADORAS DE CARNE.

Disponível em: <www.abiec.com.br> . acesso em: 05 Jan 2010.

BAUCHART, D. Lipid absorption and transport in ruminants. Journal Dairy Science, V. 76, p. 3864-3881, 1993.

BELLET, N.; ROBERT, J.C.; WILLIAMS, P.E.V. Vitamins of forage. In: GIVENS, D.I. et al. (Eds) Forage evaluation in ruminant nutrition. Wallingford, UK: CAB International, 2000. p. 373.

BIANCHINI, W; et al. Efeito do grupo genético sobre as características de carcaça e maciez da carne fresca e maturada de bovinos superprecoces. Revista Brasileira de Zootecnia. v. 36, n. 6, p. 2109-2117, 2007.

BLEZINGER, S.B. Small vitamin imbalances can be critical. Walden Farms -Cattle Today online, June, 2001.

BUCKLEY, D.J.; MORRISSEY, P.A.; GRAY, J.I. Journal of Animal Science. v. 73, p. $3122,1995$.

BURTON, G.W.; JOYCE, A.; INGOLD, K.U. Is vitamin E the only lipid-soluble, chain-breaking antioxidant in human blood plasma and erythrocyte membranes? Arch. Biochemical Biophysical, p. 221-281, 1983. 
CHAN, W.K.M. et al. Effect of dietary vitamin E supplementation on microbial load and sensory assessment in different beef cuts. Meat Science, v. 42, p. 387, 1996. CHIN, S.F. et al. Dietary sources of conjugated dienoic isomers of linoleic acid, a newly recognized class of anticarcinogens. Journal Food Comp. Anal. v. 5, p. 185-197, 1992.

CHRISTIE, W.W. The composition, structure and function of lipids in the tissue of ruminant animals. In: Ed. Christie, W.W. Lipids Metabolism in ruminant Animals. Oxford, UK: Permagon Press, 1981. p. 95-191.

COOK, M. E. CLA inhibitis the induction of prostaglandin and leukotriene synthesis. A natural substitute for non-steroidal anti-inflammatory drugs. In: INTERNATIONAL CONFERENCE ON CLA, 2001, Alesund. Proceedings... Alesund: NATURAL ASA, 2001. p. 6-7.

CORNFORTH, D. Color-its basis and importance. In: Quality Attributes and their Measurement in Meat. PEARSON A. M.; DUTSON, T.R. (Eds). Poultry and Fish Products, London: Blackie Academic, 1994. p. 34-78.

CUCKI, T.O. A eficiência do sistema superprecoce com bovinos de diferentes proporções do genótipo Bos indicus. 2006. 99f. Tese (Doutorado em Zootecnia) Universidade Estadual Paulista, Botucatu, 2006.

DESCALZO, A.M. et al. Influence of pasture or grain-based diets supplemented with vitamin E on antioxidant/oxidative balance of Argentine beef. Meat Science, v. 70, n. 1, p. 35-44, 2005.

DUCKETT, S.K. et al. Effects of time on feed on beef nutrient composition. Journal of Animal Science, v. 71, p. 2079, 1993.

EIKELENBOOM, G. et al. Effect of dietary vitamin E supplementation on beef colour stability. Meat Science, v. 54, p. 17-22, 2000.

ENSER, M. et al. Fatty acid content and composition of UK beef and lamb muscle in relation to production system and implications for human nutrition. Meat Science, v. 49, n. 3, p. 329-341, 1998.

FAUSTMAN, C. et al. Improvement of pigment and lipid stability in Holstein steers beef by dietary supplementation with vitamin E. Journal Food Science. v. 54, p. 858$862,1989$. 
FAUSTMAN, C.; CASSENS, R.G. The biochemical basis for discoloration in fresh meat: A review. Journal Muscle Foods, v. 1, p. 217, 1990a.

FELICIO, P.E. de. Fatores que influenciam na qualidade da carne bovina. In: PEIXOTO; A. M.; MOURA, J. C.; DE FARIA, V. P. (Org.). Produção de novilho de corte. Piracicaba: FEALQ, 1997. p.79-97.

FELICIO, P.E. In: I Congresso Brasileiro das Raças Zebuínas. Anais... Associação Brasileira de Criadores de Zebu. Uberaba MG, 1994. p. 63-71.

FELÍCIO, P.E.de,; CORTE, O.O.; PICCHI, V. Rendimentos de carcaça e de subprodutos de abate de novilhos das raças Nelore e Pitangueiras de dois grupos etários. In: XI Congresso da Soc. Bras. de Ciência e Tecn. de Alimentos, Anais... Recife, 1988. p.109.

FOOT, M.R. et al. The use of Vitamin $\mathrm{D}_{3}$ and its metabolites to improve beef tenderness. Journal of Animal Science, v. 82, p. 242-249, 2004.

FOX Jr., J.B. The pigments of meat. In: Price, J.F.; Schweigert, B.S. (Eds). The science of meat and meat products. 3.ed. Food and Nutrition Press, Westport, CT, p. 193-216. 1987.

FRENCH P. et al. Fatty acid composition, including conjugated linoleic acid, of intramuscular fat from steers offered grazed grass, grass silage or concentrate based diets. Journal of Animal Science, v. 78, n. 11, p. 2849- 2855, 2000.

FRIEDRICH, W. "Vitamins". New York: Walter de Grader Publisher, 1988. GRAY, J.I.; GOMAA, E.A.; BUCKLEY, D.J. Oxidative Quality and Shelf Life of Meats. Meat Science, v. 43, p. 111-123, 1996.

GRIINARI, M.; HISSA, K.; RYHANEN, E.L. Dietary sunflower oil increases conjugated linoleic acid (LAC) concentration in beef. Journal Animal Science. v. 78, p.276, 2000.

HARDWICK, P.A. In: $3^{\circ}$ Congresso Brasileiro das raças zebuinas. Anais... p.188, 1998. HEGSTED, D.M. et al. Quantitative effects of dietary fat on serum cholesterol in man. Am. Journal Clinical Nutrition. v. 17, p. 281-295, 1965.

HUTCHESON, D.P.; COLE, N.A. Vitamin E and Selenium for yearling feedlot cattle. Fed Am Soc. Exp. Biol. (Abst.) v. 68, p. 807, 1985. 
KARGES, K.; et al. Effects of supplemental vitamin $\mathrm{D}_{3}$ on feed intake, carcass characteristics, tenderness, and muscle properties of beef steers. Journal of Animal Science, v. 79, p. 2844-2850, 2001.

KOOHMARAIE, M. Muscle proteinases and meat ageing. Meat Science. v. 36, p. $93-$ 104, 1994.

KROPF, D.H. Retail packing of frozen meat. Proc. Int. Symp. National Live Stock and Meat Board, Chicago, IL. Meat Science \& Tech. Lincoln, Nebraska, p. 367, 1982. KROPF, D.H.; HUNT, M.C.; PISKE, D. Color formation and retention in fresh meat. Proc. Meat Ind. Res. Conference. National Live Stock and Meat Board, Chicago, IL, 1986, p.62.

\section{LAGE, M.E. Suplementação nutricional de novilhos Nelore com $\boldsymbol{\alpha}$-tocoferol} (Vitamina E) e seus efeitos na qualidade da carne. Campinas, 2004. 103f. Tese de Doutorado, Faculdade de Engenharia de Alimentos, UNICAMP.

LANARI, M.C.; BEVILACQUA, A.E.; ZARITZKY, N. E. Pigment modifications during freezing and frozen storage of packaged beef. Journal Food Process Engineer, v. 12 , p. $49,1989$.

LAWLESS, F. et al. Influence of breed on bovine milk cis-9, trans-11-conjugated linoleic acid content. Livest. Produc. Sci., v. 62, p. 43-49, 1999.

LEEDLE, R.A.; LEEDLE, J.A.Z.; BUTINE, M.D. Vitamin E is not degraded by ruminal microorganisms: assessment with ruminal contents from a steers fed a highconcentrate diet. Journal of Animal Science. v. 71, p. 3442, 1993.

LIU, Q.; LANARI, M.C.; SCHAEFER, D.M. A review of dietary vitamin E supplementation for improvement of beef quality. Journal of Animal Science, v. 73, p. 3131-3140, 1995.

LUCHIARI FILHO, A. Produção de carne bovina no Brasil. II SIMBOI - Simpósio sobre Desafios e Novas Tecnologias na Bovinocultura de Corte. Anais... Brasília, v. 4, p. 29- 30, 2006.

MACDOUGALL, D.B. Colour meat - its basis and importance. In: PEARSON, A.M.; DUTSON. T.R. (Ed). Quality attributes and their measurement in meat, poultry and fish product: Advances in meat research series. Black Academic and Professional, cap. 2 , vol. 9 , 1994. p. $34-78$. 
MACHLIN, J. Vitamin E. In: Machlin, L. (Ed.) Handbook of Vitamins. New York: Marcel Dekker, 1984. p. 99.

MARMER, W.N.; MAXWELL, R.J.; WILLIAMS, J.E. Effects of dietary regimen and tissue site on bovine fatty acid profiles. Journal Animal Science. v. 59, p. 109-121, 1984.

MATTSON, F.H.; GRUNDY, S.M. Comparison of effects of dietary saturated, monounsaturated, and polyunsaturated fatty acids on plasma lipids and lipoprotein in man. Journal Lipid Res., v. 26, p. 194, 1985.

McCAY, P.B.; KING, M.M.. Biochemical function. Vitamin E: Its role as a biologic free radical scavenger and its relationship to the microsomal mixed-function oxidase system. In: Machlin, L. (Ed.) Vitamin E: A Comprehensive Treatise. New York: Marcel Dekker, 1980, p.289.

McDOWELL, L.R. Vitamin E. In: L. McDowell (Ed.) Vitamins in Animal Nutrition. Academic Press, New York, 1989. p.93

MEDEIROS, S.R.D. Ácido linoléico conjugado: Teores nos alimentos e seu uso no aumento da produção de leite com maior teor de proteína e perfil de ácidos graxos modificado. Piracicaba. 98f. Tese (Doutorado) Escola Superior de Agricultura "Luiz de Queiroz", Universidade de São Paulo, Piracicaba.

MILLEN, D.D. et al. A snapshot of management practices and nutritional recommendations used by feedlot nutritionists in Brazil. Journal of Animal Science, v.87, p.3427-3439, 2009.

MILLER, M.F. et al. Consumer thresholds for establishing the value of beef tenderness. Journal of Animal Science. v.79, p. 3062-3068, 2001.

MITSUMOTO, M. et al. Dietary vitamin and supplementation shifted weight loss from drip to cooking loss in fresh beef longissimus during display. Journal of Animal Science, v. 73, p. 2289-2294, 1995.

MONTGOMERY, J.L. et al. The use of vitamin $\mathrm{D}_{3}$ to improve beef tenderness. Journal of Animal Science, v. 78, p. 2615-2621, 2000a.

MONTGOMERY, J.L. et al., Effect of vitamin $\mathrm{D}_{3}$ supplementation level on the postmortem tenderization of beef from steers. Journal of Animal Science, v. 8, p. 971981, 2002. 
MONTGOMERY, J.L.; ALLEN, V.G.; POND, K.R. Tasco-Forage: IV. Influence of a seaweed extract applied to tall fescue pastures on sensory characteristics, shelf-life, and vitamin E status in feedlot-finished steers. Journal of Animal Science. v. 79, p. 884894, 2001.

MONTGOMERY, J.L.; KING, M.B.; GENTRY, J.G. Supplemental vitamin D3 concentration and biological type of steers. Journal of Animal Science, v. 82, p. 2092 2104, 2004.

MORRISSEY, P.A. et al. Vitamin E and meat quality. Proceedings of the Nutrition Society. v. 53, p. 289-295, 1994.

MORRISSEY,P.A. et al. Lipid Stability in Meat and Meat Products. Meat Science, v. 49, p.73-86, 1998.

NATIONAL RESEARCH COUNCILL. Nutrient requirements of dairy cattle. 7.ed. Washington: National Academy Press. 2001.331p.

NATIONAL RESEARCH COUNCILL. Vitamin Tolerance of domestic Animals.

7.ed. Washington: National Academy Press. 1996. 242p.

NORMAN, G. Effect of breed and nutrition on the productive traits of zebu, charolais and crossbreed beef cattle in south-east Brazil. III - Meat quality. Meat Science.v. 6, p. 79, 1982.

NUNES, I.J. In: Nutrição Animal Básica, Editora FEP-MVZ, 2.ed., 1998.

PARDI, M.C.; SANTOS, I.F. dos; SOUZA, E.R. de et al. Ciência, higiene e tecnologia da carne. Anais... Goiania: UFG, 1995.

PARIZA, M.W.; PARK, Y.; COOK, M.E. The biologically active isomers of conjugated linoleic acid. Progr. in Lip. Res. v.40, p. 283-298, 2001.

PAZ, C.C.P. de; LUCHIARI FILHO, A. Melhoramento genético e diferenças de raças com relação à qualidade da carne bovina. Pecuária de Corte, n.101, 2000. p. 58-63. PEDREIRA, A.C.M.S. et al. Quality characteristics of Longissimus muscle from Bos indicus animals treated whit Vitamin $\mathrm{D}_{3}$. Scientia Agricola. v. 60, n. 4, p. 637-642, 2003.

RESTLE, J. et al. Efeito da raça e heterose para qualidade da carcaça e da carne de novilhos terminados em confinamento. In: REUNIÓN LATINOAMERICANA DE PRODUCCIÓN ANIMAL, 14, 1995, Mar del Plata, Memorias... Balcare: ALPA, 1995. n. 3-4, p. 854-856, 1995. 
RESTLE, J. et al. Qualidade da carne de animais Hereford e suas cruzas com Nelore, abatidos aos quatorze meses. In: REUNIÃO ANUAL DA SOCIEDADE BRASILEIRA DE ZOOTECNIA, 34, 1997, Juiz de Fora. Anais... Juiz de Fora: Sociedade Brasileira de Zootecnia, 1997. p.196-198.

RESTLE, J.; VAZ, F.N. Confinamento de bovinos definidos e cruzados. In: LOBATO, J.F.P.; BARCELLOS, J.O.J.; KESSLER, A.M. (Eds.) Produção de bovinos de corte. Anais... Porto Alegre: Edipucrs, 1999. p.141-167.

RESTLE, J.; VAZ, F.N. Tendências de mercado e entraves tecnológicos para a cadeia produtiva da carne bovina. In: MELLO, N.A.; ASSMANN, T.S. (Eds.) Integração lavoura- pecuária no sul do Brasil. Anais... Pato Branco: IAPAR/CEFET, 2002. p.167188.

RUCKER, R.B; MORRIS, J.G. In: Clinical Biochemistry of Domestic Animal. 15.ed., cap. 24, 1997. p.703-718.

SANDERS, S.K. et al. Vitamin E supplementation of cattle and shelf-life of beef for the Japanese market. Journal of Animal Science, v. 75, p. 2634-2640, 1997.

SMITH, G.C. et al. The final report of the National Beef Quality Audit. Colorado State Univ., Fort Collins; Texas A\&M Univ. CollegeStation; and Oklahoma State Univ., Stillwater. NCA, Englewood, CO, 1995.

SOUZA, A.A. Perfil de ácidos graxos e concentração de CLA no tecido adiposo de bovinos de corte de diferentes grupos genéticos no modelo biológico superprecoce. Botucatu. 73f. Tese (Doutorado) Faculdade de Medicina Veterinária e Zootecnia, Universidade Estadual Paulista, Botucatu.

SWANEK, S.S. et al. Supplemental vitamin $\mathrm{D}_{3}$ and beef tenderness. Animal Science Research Report, Oklahoma State University, p.59-66, 1999a.

SWANEK, S.S.; MORGAN, J.B.; OWENS, F.N. et al. Vitamin D3 supplementation of beef steers increases longissimus tenderness. Journal of Animal Science. v. 77, p. 874$881,1999$.

VARELA, A., OLIETE, B.; MORENO, T. et al. Effect of pasture finishing on the meat characteristics and intramuscular fatty acid profile of steers of the Rubia Gallega breed. Meat Science, v. 67, p. 515-522, 2004.

WARRIS, P.D.; and RHODES, D.N.; Haemoglobin concentrations in beef. Journal Science Food Agricultural. v. 28, p. 931-934, 1977. 
WEISS, W.P. Effect of forage to concentrate ratio on disappearance of vitamins A and E during in vitro ruminal fermentation. Journal Dairy Science. v. 78, p. 1837, 1995. WEISS, W.P. Requirements of fat-soluble vitamins for dairy cows: a review. Journal of Dairy Science, v. 81, n. 9, p. 2493-2501, 1998.

WHEELER, T.L.; SAVELL, J.W.; CROOS, H.R. Mechanisms associated with the variation in tenderness of meat from Brahman and Hereford cattle. Journal of Animal Science, v.68, n. 12, p. 4206-4220, 1990.

WHIPPLE, G. et al. Evaluation of attributes that affect longissimus muscle tenderness in Bos taurus and Bos indicus cattle. Journal of Animal Science, v. 68, p. 2716-2728, 1990.

WILLIAMS, C.M. Dietary fatty acids and human health. Ann. Zootech. v. 49, p. 165180, INRA, 2000.

WOOD, J.D. et al. Effects of fatty acids on meat quality: a review. Meat Science, v. 66, n. 1, p. 21-32, 2003.

YANG, A.; LANARI, M.C.; BREWSTER, M. et al. Lipid stability and meat colour of beef from pasture- and grain-fed cattle with or without vitamin E supplement. Meat Science. v. 60, p. 41-50, 2002.

ZEOULA L.M.; GERON, L.J.V. Vitaminas. In: BERCHIELLI, T.T.; PIRES, A.V.; OLIVEIRA, S. G. (Ed.). Nutrição de Ruminantes. São Paulo: Funep, , 2006. p.111150 .

ZERBY, H. N. et al. Effects of muscle a-tocopherol level and surface microbiological contamination on retail case life of fresh beef from the US, Japan and Australia. Meat Science, v. 52, p. 111-118, 1999. 
CAPÍTULO 2 


\section{Desempenho, características de carcaça e atributos da carne de bovinos jovens confinados suplementados com vitaminas D e E.}

Resumo: O experimento foi conduzido no confinamento da Unesp/Botucatu, com o objetivo de avaliar a influência da suplementação das vitaminas D e E sobre o desempenho, características de carcaça e atributos de carne de bovinos jovens confinados. Foram utilizados 36 machos inteiros, 18 Nelore (NE) e 18 Canchim (CC); desmamados aos sete meses de idade, com peso vivo médio de 234,53 $\pm 22,15$ e 248,13 $\pm 34,67 \mathrm{~kg}$, respectivamente. Os animais foram confinados por 134 dias. Aos quarenta e sete dias pré-abate, nove animais NE e nove animais CC, foram suplementados com 1300 UI/vitamina E/dia e 10 dias antes do abate, os mesmos animais foram suplementados com 7,5 x $10^{6} \mathrm{UI} /$ vitamina $\mathrm{D}_{3} /$ dia. No último dia da suplementação, foram colhidas amostras de sangue dos animais, para avaliar o cálcio plasmático. $\mathrm{O} \mathrm{pH}$ da carcaça foi mensurado à zero e $24 \mathrm{hs}$ após o abate. Na desossa, foram colhidas amostras de Longissimus, entre a $12^{\mathrm{a}}$ e $13^{\mathrm{a}}$ costelas, para análise de força de cisalhamento, perdas por cocção, índice de fragmentação miofibrilar, lipídeos totais, concentração de vitamina D e E na carne e exposição sob condições simuladas de varejo. A cor e o $\mathrm{pH}$ da carne, foram mensurados diariamente nas amostras expostas. No primeiro e no último dia de exposição foram colhidas amostras da gordura subcutânea, para análise do perfil de ácidos graxos. Não houve efeito da suplementação de vitaminas D e E sobre o desempenho, características de carcaça e atributos da qualidade da carne, porém houve efeito para cálcio plasmático. A suplementação de vitaminas $\mathrm{D}$ e E, não foi efetiva para melhorar o desempenho, as características de carcaça e os atributos de qualidade da carne de bovinos jovens confinados.

Palavras chave: canchim, concentração de cálcio plasmático, condições simuladas de varejo, maciez, nelore, perfil de ácidos graxos 


\title{
Performance, carcass characteristics and meat quality of feedlot bullocks supplemented with vitamins $D$ and $E$.
}

\begin{abstract}
The experiment was conducted at Unesp/Botucatu feedlot, with the objective to evaluate the supplementation of vitamin D and E on performance, carcass characteristics and meat quality of feedlot bullocks. It was used 36 animals, 18 Nellore (NE) and 18 Canchim (CC), weaned at seven months and average initial body weight of $234.53 \pm 22.15$ and $248.13 \pm 34.67 \mathrm{~kg}$, respectively, fed for134 days. At the forty seventh day prior slaughter, nine NE and nine CC were supplemented with 1300 IU/vitamin E/day and 10 days prior slaughter, the same animals were supplemented with $7.5 \times 10^{6} \mathrm{IU} /$ vitamin $\mathrm{D}_{3} /$ day. At last day of supplementation, blood samples were taken to evaluate plasmatic calcium. Carcass $\mathrm{pH}$ was measured at 0 and $24 \mathrm{hrs}$ after slaughter. At boning process, Longissimus samples were collected between $12^{\text {th }}$ and $13^{\text {th }}$ ribs for sear force, cooking loss, miofibrilar fragmentation index, total lipids, vitamin D and $\mathrm{E}$ concentrations, and retail conditions storage simulation. Meat color and $\mathrm{pH}$ of the samples were daily measured. Fatty acid profile samples were collected at first and last day of retail condition storage simulation. There was no effect of vitamin D and $\mathrm{E}$ on feedlot performance, carcass characteristics and meat quality, although plasmatic calcium effect was observed. In conclusion, vitamin D and $E$ were not effective to enhance feedlot performance, carcass characteristics and meat quality of feedlot bullocks.
\end{abstract}

Keywords: canchim, fatty acid profile, nellore, plasmatic calcium concentration, retail condition storage simulation, tenderness 


\section{Introdução}

O Brasil exportou no ano de 2009, 1,2 milhões de toneladas de carne, sendo que $67 \%$ foram in natura. Estes valores movimentaram a economia brasileira em 4U\$ bilhões de dólares aproximadamente (ABIEC, 2009). Contudo, para ser considerada uma carne de alta qualidade, alguns fatores são levados em consideração, como suculência, sabor, cor, maciez e durabilidade.

Diante deste contexto, é preciso promover mudanças significativas por meio de estratégias alimentares, sendo que a suplementação de vitaminas pré-abate, pode ser uma opção diante do desafio de obter carnes com qualidade. Deste modo, o fornecimento de vitamina D disponibiliza cálcio suficiente para ativar as proteases dependentes de cálcio ( $\mu$ - e m-calpaínas) e pode acelerar o processo de amaciamento da carne (Swanek et al., 1999; Montgomery et al., 2000a). Além disso, a suplementação de vitamina $\mathrm{D}$ pode ser usada para acelerar o processo de maturação e melhorar a maciez de produtos cárneos fornecidos no varejo (Vargas et al. (1999). Já a vitamina E, pode atuar como um potente antioxidante natural para evitar a oxidação lipídica (Faustman et al., 1989), e assim, pode melhor a aparência e a durabilidade do produto cárneo.

Vargas et al. (1999), reportaram que ao suplementar novilhos com uma mistura de vitamina D e E $\left(6 \times 10^{6} \mathrm{UI} /\right.$ dia, durante 7 dias antes do abate e $1000 \mathrm{UI} /$ dia, durante 54 dias antes do abate), encontraram maior peso vivo final, melhor coloração, maior extensão da vida de prateleira, menor força de cisalhamento, maior maciez em um menor tempo de maturação, em relação ao controle (sem suplementação).

Diante destes resultados, objetivou - se avaliar se a suplementação de vitaminas D e E, seria capaz de reduzir o tempo de 7 dias de maturação para uma carne sem maturação, e se a suplementação iria interferir no desempenho, características de 
carcaça e características de qualidade da carne de bovinos jovens, exposta sob condições simuladas de varejo.

\section{Material e Métodos}

O estudo foi conduzido na Unesp, Faculdade de Medicina Veterinária e Zootecnia, campus de Botucatu, nas instalações do confinamento experimental. Foram utilizados 36 animais machos inteiros, pertencentes a dois grupos genéticos, sendo 18 da raça Nelore (NE) e 18 da raça Canchim (5/8 Charolês, 3/8 Nelore) (CC), com idade média de 7 meses e peso vivo inicial médio de $234,53 \pm 22,15$ e $248,13 \pm 34,67 \mathrm{~kg}$, respectivamente. Os animais foram confinados por um período de 135 dias, sendo 27 dias de adaptação à dieta e as instalações.

No início do experimento, todos os animais foram pesados (PVI), desverminados e vacinados contra doenças virais e bacterianas.

Os animais foram distribuídos aleatoriamente em 4 baias, sendo 9 animais NE com suplementação de vitamina D e E e 9 animais NE do grupo controle (sem adição de vitamina D e E), 9 animais CC com suplementação de vitamina D e E e 9 animais $C C$ do grupo controle (sem adição de vitamina D e E);

As dietas utilizadas foram formuladas segundo o sistema Cornell Net Carbohydrate and Protein System 5.0. 26 (CNCPS, 2000), com estimativa de ganho de peso diário de 1,3 a 1,6 kg/animal (Tabela 1). O fornecimento diário foi fracionado em duas vezes ( $40 \%$ pela manhã e $60 \%$ à tarde).

Os animais foram pesados a cada 28 dias aproximadamente, após um período de jejum de sólidos de 16 horas, para monitoramento do ganho diário de peso vivo. $\mathrm{O}$ crescimento e deposição do tecido adiposo foram monitorados por ultrassonografia em 
cada período, por meio de uma amostragem, apenas para determinar o ponto de abate dos animais.

Tabela 1. Ingredientes e composição química das dietas experimentais fornecidas durante o estudo

\begin{tabular}{|c|c|c|c|c|c|}
\hline \multicolumn{6}{|c|}{ Dietas Experimentais } \\
\hline Fases & $\mathrm{AI}^{2}$ & $\mathrm{AII}^{3}$ & $\mathrm{AIII}^{4}$ & Crescimento & Terminação \\
\hline Duração das fases & 7 dias & 7 dias & 13 dias & 66 dias & 41 dias \\
\hline $\mathrm{NC}^{5}$ & $57 \%$ & $63 \%$ & $67 \%$ & $72 \%$ & $80 \%$ \\
\hline \multicolumn{6}{|c|}{ Porcentagem de Inclusão dos Ingredientes (\%MS) } \\
\hline \multicolumn{6}{|l|}{ Item $^{1}$} \\
\hline Bagaço de Cana & 26,94 & 23,48 & 20,71 & 21,77 & 13,61 \\
\hline Feno Coast-cross & 15,37 & 14,02 & 12,58 & 5,12 & 4,54 \\
\hline SGUM & 23,14 & 27,74 & 32,21 & 36,20 & 47,52 \\
\hline Polpa Cítrica & 12,33 & 12,96 & 13,34 & 15,25 & 19,98 \\
\hline Farelo de Soja & 20,70 & 20,27 & 19,63 & 20,14 & 12,85 \\
\hline Uréia & 0,46 & 0,46 & 0,46 & 0,47 & 0,43 \\
\hline Sal Mineral* & 1,07 & 1,07 & 1,07 & 1,05 & 1,08 \\
\hline \multicolumn{6}{|c|}{ Composição Nutricional (\%MS) } \\
\hline MS & 74 & 75 & 75 & 74 & 75 \\
\hline PB & 15,6 & 15,7 & 15,8 & 16,0 & 13,8 \\
\hline FDN & 37,1 & 33,6 & 30,3 & 25,9 & 19,2 \\
\hline peFDN & 32 & 28 & 25 & 21 & 15 \\
\hline NDT & 71 & 73 & 75 & 76 & 80 \\
\hline Cálcio & 0,54 & 0,54 & 0,54 & 0,55 & 0,62 \\
\hline
\end{tabular}

${ }^{1}$ SGUM: silagem de grão úmido de milho; MS: matéria seca; PB: proteína bruta; FDN: fibra em detergente neutro; peFDN: fibra em detergente neutro fisicamente efetiva; NDT: nutrientes digestíveis totais.

${ }^{2}$ AI: adaptação I; ${ }^{3}$ AII: adaptação II; ${ }^{4}$ AIII: adaptação III.

${ }^{5} \mathrm{NC}$ : nível de concentrado.

${ }^{*}$ Sal mineral contendo uréia.

Com 47 dias pré-abate, nove animais $\mathrm{NE}$ e nove animais $\mathrm{CC}$, receberam diariamente $1300 \mathrm{UI} /$ animal de vitamina E (Acetato de alfa- tocoferol - Mcassab ${ }^{\circledR}$ ). Aos 10 dias pré-abate, os mesmos animais receberam 7,5 x $10^{6} \mathrm{UI} /$ animal de vitamina 
$\mathrm{D}$ (Vitamina $\mathrm{D}_{3}-$ Mcassab ${ }^{\circledR}$ ). As vitaminas foram misturadas a $100 \mathrm{~g}$ de farelo de soja e foram fornecidas no cocho sobre o trato, enquanto que o grupo controle recebeu apenas $100 \mathrm{~g}$ do farelo de soja, sobre o trato.

No último dia de suplementação, antes dos animais serem alimentados, foram colhidas amostras de sangue de cada animal em tubos a vácuo (Vacutainer) (10 ml), contendo heparina, para avaliar a concentração de cálcio plasmático $(\mathrm{Ca})$. Os tubos foram armazenados em recipiente com gelo durante a coleta, transportados para o laboratório e processados logo após a colheita. As amostras foram centrifugadas por 15 minutos, para separação do plasma. Em seguida, $4 \mathrm{ml}$ de plasma foram colhidos em 2 ependorfs de $2 \mathrm{ml}$ cada, e estocados a $-20^{\circ} \mathrm{C}$ (Montgomery et. al., 2004). As amostras foram analisadas por espectrometria de absorção atômica.

Após o término do período experimental, antes do embarque para o abate, os animais foram pesados com um período de jejum de sólidos de 16 horas, para obtenção do peso vivo final (PVF).

Os animais foram abatidos em frigorífico comercial quando atingiram o mínimo de $4 \mathrm{~mm}$ de gordura subcutânea, visualizadas no ultrassom. Foi obtido o peso de carcaça quente (PCQ), e em seguida foi realizada a medida de $\mathrm{pH}$ inicial $(\mathrm{pH} 0)$ das meias carcaças esquerdas na região entre a $12^{a}$ e $13^{a}$ costela do músculo Longissimus. Com os dados de PCQ e PVF, calculou-se o rendimento de carcaça (RC), em porcentagem (\%). Após 24 horas de resfriamento das carcaças na câmara fria foi realizada a medida de $\mathrm{pH}$ final $(\mathrm{pH} 24)$.

Durante a desossa, foram colhidas sete amostras de $2,5 \mathrm{~cm}$ do músculo Longissimus entre a $12^{\mathrm{a}}$ e $13^{\mathrm{a}}$ costelas, de cada animal. Uma amostra de cada animal foi usada separadamente para cada análise. Foram retiradas amostras para análises de força de cisalhamento e índice de fragmentação miofibrilar no tempo zero (sem maturação), 
lipídeos totais e vitamina $\mathrm{D}$ e E na carne, foram embaladas a vácuo individualmente e congeladas em freezer doméstico $\left(-20^{\circ} \mathrm{C}\right)$. Duas amostras de cada animal foram embaladas a vácuo individualmente e maturadas entre $0^{\circ} \mathrm{C}$ e $2^{\circ} \mathrm{C}$, por 7 dias e posteriormente congeladas a $-20^{\circ} \mathrm{C}$, uma para análise de força de cisalhamento e outra para índice de fragmentação miofibrilar no tempo sete (aos sete dias de maturação).

A última amostra colhida de cada animal foi embalada a vácuo individualmente, para avaliar a cor, $\mathrm{pH}$ e o perfil de ácido graxo da carne exposta sob condições simuladas de varejo (presença de oxigênio da embalagem permeável e exposta à iluminação). Estas amostras não foram maturadas e nem congeladas. Contudo, foram analisadas logo após o abate.

As amostras foram individualmente, desembaladas do vácuo, identificadas, colocadas em uma bandeja de poliestireno revestida com filme plástico de PVC, e mantidas em um balcão expositor frigorífico, específico para carnes, com temperatura variando entre $0^{\circ} \mathrm{C}$ e $4^{\circ} \mathrm{C}$ e com luminosidade controlada de $1251 \mathrm{x}$, simulando condições de varejo.

Nos dias 0 (P0), 1 (P1), 2 (P2), 3 (P3), 6 (P6) e 7 (P7) de exposição, as amostras foram desembaladas, expostas ao ambiente por 20 a 30 minutos para oxigenação da mioglobina, e então, foram realizadas as medidas de cor e $\mathrm{pH}$. Posteriormente, as amostras foram reembaladas com filme plástico de PVC e colocadas novamente ao balcão expositor. A cor dos músculos foi determinada com o auxílio de um colorímetro portátil (modelo MiniScan XE, marca Hunter Lab), com fonte de luz D65, ângulo de observação de $10^{\circ}$ e abertura da célula de medida de $30 \mathrm{~nm}$, utilizando-se a escala do sistema CIELAB (L*, a* e b*). A calibração do aparelho foi realizada antes da leitura das amostras com um padrão branco e outro preto. As medidas de cor foram realizadas 
em três diferentes regiões da amostra, considerando a média como valor determinado. Para as medidas de $\mathrm{pH}$, foi utilizado um peagômetro acoplado num termômetro digital.

Para análise de perfil de ácidos graxos, foi coletada a gordura subcutânea de cada amostra exposta, no dia zero (P0) e no último dia de exposição (P7), para verificar se houve mudança no perfil de ácidos graxos, durante o período de exposição. As amostras de gordura foram então, congeladas em freezer doméstico $\left(-20^{\circ} \mathrm{C}\right)$. A extração e avaliação dos lipídeos totais foram realizadas de acordo com a metodologia modificada de Hara \& Radin (1978), com uso de hexano/isopropanol 3:2 (v/v). Para a transesterificação dos ácidos graxos foi utilizada metodologia descrita por Christie (1982), com modificações, utilizando solução metanólica de metóxido de sódio.

Para análise da força de cisalhamento, as amostras foram descongeladas em geladeira por 24 horas, foram pesadas ( $\mathrm{Pi}$ ), assadas em forno elétrico até atingirem a temperatura interna de $71^{\circ} \mathrm{C}$, foram pesadas novamente (Pf) e resfriadas por 24 horas. Calculou-se então, as perdas por cocção (PPC), conhecendo-se o peso antes (Pi) e depois (Pf) do cozimento. Após as 24 horas de resfriamento, foram retirados 6 cilindros, com um vazador de $1,27 \mathrm{~cm}$ de diâmetro acoplado a uma furadeira elétrica. Estes cilindros foram colocados em um aparelho de Warner-Bratzler Shear Force, e assim, mediu-se a força necessária para cortar transversalmente cada cilindro. Em seguida, calculou-se a média de seis medidas, considerando a média como valor determinado, segundo Wheeler et al. (1997).

A determinação do MFI foi realizada conforme Culler et al. (1978). A porcentagem de lipídeos totais foi determinada segundo Bligh \& Dyer (1959).

A determinação da quantidade de vitamina $\mathrm{D}$ e E foram realizadas utilizando-se metodologia por HPLC após hidrólise e quantificação por detector de UV-VIS, proposta por Gong \& Ho (1997). Cinqüenta gramas de amostra do músculo Longissimus foram 
colhidos no momento do abate e congelados em freezer a $-20^{\circ} \mathrm{C}$ para posterior análise da concentração das vitaminas $\mathrm{D}$ e E. As amostras foram misturadas à $30 \mathrm{ml}$ de $\mathrm{KOH}$ etanólico e então saponificadas a $80^{\circ} \mathrm{C}$ durante 20 minutos. Foram extraídas duas amostras dessa mistura com 10ml de n-hexano. Posteriormente, as amostras extraídas foram secas, reconstituídas com $1 \mathrm{ml}$ de fase móvel e injetado em cromatógrafo numa alíquota de $5 \mu 1$. As análises foram procedidas em cromatografia líquida em coluna de $250 \mathrm{X} 4.65 \mid \mathrm{xm} \mathrm{C18}$ (Alltech) com detector UV 250. O comportamento das análises será o mesmo para as vitaminas D e E por se tratarem ambas de vitaminas lipossolúveis.

O delineamento experimental utilizado foi o inteiramente casualizado, em arranjo fatorial 2 x 2, sendo 2 (grupos genéticos: Nelore e Canchim) e 2 (tratamentos: suplementação ou não com vitaminas).

Com relação ao modelo estatístico experimental, os animais individualmente foram considerados as unidades experimentais. Foram realizados testes de normalidade e de heterogeneidade dos tratamentos antes de se proceder a análise de variância e quando necessário, os dados foram transformados. Foi utilizado o teste de Tukey para comparação entre médias e os resultados foram considerados significantes a $\mathrm{P}<0,05$.

As variáveis de desempenho e características de carcaça estudadas foram analisadas como arranjo fatorial 2 × 2 pelo PROC MIXED do SAS (2003) de acordo com o modelo 1.

\section{MODELO 1:}

$Y_{i j k}=u+G R_{i}+T_{j}+G R^{*} T_{i j}+e_{i j k}$, onde:

$\mathrm{Y}_{\mathrm{ijk}}=$ característica medida no animal $\mathrm{k}$, do tratamento $\mathrm{j}$ e grupo genético $\mathrm{i}$;

$\mathrm{u}=$ constante inerente as observações;

$\mathrm{GR}=$ efeito do grupo genético $\mathrm{i}$, sendo $\mathrm{i}=1$ : Nelore, 2 : Canchim 
$\mathrm{T}=$ efeito do tratamento $\mathrm{j}$, sendo $\mathrm{j}=1$ : com suplementação de vitaminas e 2 : sem suplementação de vitaminas;

$\mathrm{GR}^{*} \mathrm{~T}=$ efeito da interação entre grupo genético e tratamento;

$\mathrm{e}_{\mathrm{ijk}}=$ erro experimental associado a observação $\mathrm{Y}_{\mathrm{ijk}}\left(0 ;{ }^{2}{ }^{2}\right)$.

As análises de maciez da carne e perfil de ácidos graxos da gordura subcutânea do músculo Longissimus envolvendo medidas repetidas no tempo (maturação em 0 e 7 dias) foram analisados como arranjo fatorial 2 × 2 pelo PROC MIXED do SAS (2003) de acordo com o modelo 2 .

MODELO 2:

$Y_{i j k l}=u+G R_{i}+T_{j}+G R^{*} T_{i j}+A\left(G R^{*} T_{i j}\right)+P_{l}+P^{*} G R_{i l}+P^{*} T_{j l}+P^{*} G R^{*} T_{i j l}+e_{i j k l}$ , onde:

$\mathrm{Y}_{\mathrm{ijkl}}=$ característica medida no animal $\mathrm{k}$, do tratamento $\mathrm{j}$, grupo genético i e período 1;

$\mathrm{u}=$ constante inerente as observações;

$\mathrm{GR}=$ efeito do grupo genético $\mathrm{i}$, sendo $\mathrm{i}=1$ : Nelore, 2 : Canchim

$\mathrm{T}=$ efeito do tratamento $\mathrm{j}$, sendo $\mathrm{j}=1$ : com suplementação de vitaminas e 2 : sem suplementação de vitaminas;

$\mathrm{GR}^{*} \mathrm{~T}=$ efeito da interação entre grupo genético e tratamento;

$\mathrm{A}\left(\mathrm{GR}^{*} \mathrm{~T}\right)=$ erro experimental "a" associado à observação $\mathrm{Y}_{\mathrm{ijk}}$;

$\mathrm{P}=$ efeito do período de avaliação, sendo l=1: 0 dias e 2: 7 dias.

$\mathrm{P}^{*} \mathrm{GR}=$ efeito de interação entre períodos e grupos genético;

$\mathrm{P} * \mathrm{~T}=$ efeito de interação entre períodos e tratamentos;

$\mathrm{P}^{*} \mathrm{GR} * \mathrm{~T}=$ efeito de interação entre períodos, grupos genéticos e tratamentos;

$\mathrm{e}_{\mathrm{ijkl}}=$ erro experimental "b” associado a observação $\mathrm{Y}_{\mathrm{ijkl}}\left(0 ;{ }_{e}^{2}\right)$. 
As características referentes à durabilidade da carne exposta sob condições simuladas de varejo, com medidas repetidas no tempo $(0,1,2,3,6$ e 7 dias $)$ foram analisados como arranjo fatorial 2 × 2 pelo PROC MIXED do SAS (2003) de acordo com o modelo 3. Para este modelo, quando efeitos foram significativos, as médias foram comparadas utilizando-se contrastes pela opção CONTRAST do SAS (2003).

\section{MODELO 3:}

Igual ao modelo 2, com exceção de:

$\mathrm{P}=$ efeito da durabilidade da carne sob refrigeração, sendo l=1: 0 dia, 2: 1 dia, 3: 2 dias, 4: 3 dias, 5: 6 dias e 6: 7 dias.

Cada uma das variáveis respostas, ligadas aos modelos 2 e 3 , foi submetida a 10 estruturas de covariância: AR(1), ARH(1), ANTE(1), TOEP, TOEPH, CS, CSH, UN, UNR e HF. A estrutura de covariância que rendeu o menor valor de AIC (Akaike Criterion) para cada variável foi escolhida por acomodar melhor a matriz de dados.

\section{Resultados e discussão}

Não foi observado efeito do grupo genético para PVI, PVF, GDP, PCQ, pH0, pH24, com exceção do RC e LT, onde o NE apresentou maiores valores em relação ao CC. Este resultado já era esperado, visto que, a raça NE caracteriza-se por ser uma raça mais precoce em deposição de gordura em relação ao CC. Portanto, pelo fato do NE apresentar deposição de gordura precocemente, termina mais rápido, apresentando maior rendimento de carcaça e maior teor de gordura na carne, em relação CC (Menezes et al., 2005). Não foi observado efeito da suplementação de vitaminas D e E, para todas as variáveis de desempenho e características de carcaça avaliadas (Tabela 2). 
Tabela 2. Desempenho e características de carcaça de novilhos Nelore e Canchim, suplementados ou não com vitaminas $\mathrm{D}$ e $\mathrm{E}$

\begin{tabular}{lccccccc}
\hline & \multicolumn{2}{c}{$\mathrm{GG}^{2}$} & \multicolumn{2}{c}{ VIT $^{3}$} & \multicolumn{2}{c}{ Valor P } & EPM $^{4}$ \\
\hline Item $^{1}$ & $\mathrm{NE}$ & $\mathrm{CC}$ & $\mathrm{CV}$ & $\mathrm{SV}$ & $\mathrm{GG}$ & $\mathrm{VIT}$ & \\
\hline PVI, kg & 234,53 & 248,13 & 242,00 & 240,65 & 0,18 & 0,89 & 29,97 \\
PVF, kg & 371,33 & 384,11 & 379,11 & 376,33 & 0,38 & 0,84 & 43,63 \\
GPD, kg & 1,27 & 1,26 & 1,27 & 1,26 & 0,91 & 0,84 & 0,20 \\
PCQ, kg & 198,17 & 201,27 & 199,41 & 200,02 & 0,70 & 0,93 & 24,13 \\
RC, \% & 53,35 & 52,40 & 52,59 & 53,15 & 0,04 & 0,22 & 1,35 \\
pH0 & 6,83 & 6,88 & 6,84 & 6,87 & 0,39 & 0,58 & 0,17 \\
pH24 & 5,55 & 5,59 & 5,57 & 5,57 & 0,51 & 0,98 & 0,17 \\
LT & 1,4 & 0,9 & 1,2 & 1,1 & $<0,01$ & 0,44 & 0,01 \\
\hline
\end{tabular}

${ }^{1}$ PVI: peso vivo inicial; PVF: peso vivo final; GDP: ganho de peso; PCQ: peso de carcaça quente; RC: rendimento de carcaça; $\mathrm{pH} 0$ : $\mathrm{pH}$ inicial da carcaça; $\mathrm{pH} 24$ : $\mathrm{pH}$ final da carcaça, LT: lipídeos totais.

${ }^{2}$ GG: grupo genético; NE: Nelore; CC: Canchim.

${ }^{3}$ VIT: Vitamina; CV: com suplementação de vitamina; SV: sem suplementação de vitamina. ${ }^{4}$ EPM: Erro Padrão Médio.

Não houve efeito do grupo genético para FC, PPC e Ca, exceto para MFI, onde CC apresentou maior valor em relação ao NE (Tabela 3), conferindo uma maior maciez para a carne desses animais. Apesar dos dados de FC, não apresentarem resultados estatisticamente diferentes para os grupos genéticos, os animais CC apresentaram numericamente menor valor em relação ao NE (3,82 vs. 4,12, respectivamente) (Tabela 3), conferindo-lhes uma carne mais macia. Independente da raça, os valores de FC encontram-se dentro aceitável para carne macia, abaixo de $5 \mathrm{~kg}$ (Felício, 1997). Esses valores de MFI e FC encontrados podem ser explicados, pelo fato dos animais zebuínos, como o NE, apresentarem maiores concentrações de calpastatinas, inibidoras das proteases dependentes de cálcio ( $\mu$-e m-calpainas), responsáveis pelo amaciamento da carne (Montgomery et al., 2000a), em relação aos animais CC. 
Tabela 3. Características de maciez do músculo Longissimus de novilhos Nelore e Canchim suplementados ou não com vitaminas D e E

\begin{tabular}{|c|c|c|c|c|c|c|c|c|c|c|c|}
\hline & \multicolumn{2}{|c|}{$\mathrm{GG}^{2}$} & \multicolumn{2}{|c|}{$\mathrm{VIT}^{3}$} & \multicolumn{2}{|c|}{$\mathrm{PER}^{4}$} & \multicolumn{3}{|c|}{ Valor de $\mathrm{P}$} & $\overline{E P M}$ & $\mathrm{INT}^{6}$ \\
\hline Item $^{1}$ & $\mathrm{NE}$ & $\mathrm{CC}$ & $\mathrm{CV}$ & SV & Zero & Sete & GG & VIT & MAT & & \\
\hline $\mathrm{FC}$ & 4,12 & 3,82 & 4,00 & 3,94 & 4,19 & 3,76 & 0,14 & 0,76 & 0,02 & 0,14 & $\mathrm{NS}^{7}$ \\
\hline PPC & 24,18 & 23,21 & 23,57 & 23,82 & 23,22 & 24,17 & 0,33 & 0,79 & 0,34 & 0,69 & NS \\
\hline MFI & 62,61 & 69,07 & 63,87 & 67,82 & 59,58 & 72,09 & 0,02 & 0,16 & $<0,0$ & 2,71 & 0,04 \\
\hline $\mathrm{Ca}$ & 172,2 & 169,9 & 189,7 & 152,4 & - & - & 0,79 & $<0,01$ & - & 26,54 & NS \\
\hline
\end{tabular}

${ }^{\mathrm{T}}$ FC: Força de cisalhamento, em kg; PPC: Perdas por cocção, em \%; MFI: Índice de fragmentação miofibrilar, Ca: concentração de cálcio plasmático em mg/L.

${ }^{2}$ GG: grupo genético; NE: Nelore; CC: Canchim.

${ }^{3}$ VIT: Vitamina; CV: com suplementação de vitamina; SV: sem suplementação de vitamina ${ }^{4}$ PER: período de maturação.

${ }^{5}$ EPM: Erro Padrão Médio.

${ }^{6} \mathrm{INT} .:$ interação.

${ }^{7}$ NS: Não Significativo.

Não houve efeito de suplementação de vitaminas D e E, para nenhuma das características de maciez, exceto para $\mathrm{Ca}$. Os animais suplementados apresentaram $\mathrm{Ca}$ maior que os não suplementados, porém não houve redução na FC (Tabela 3). De acordo com os dados encontrados por Scanga et al. (2001), que não observaram redução na $\mathrm{FC}$, mesmo que a suplementação de vitamina $\mathrm{D}_{3}$ tenha elevado a $\mathrm{Ca}$. Esses resultados podem ter ocorrido, porque a suplementação de vitaminas D e E, pode ser efetiva para melhorar a maciez da carne, quando bovinos tendem a apresentar carne mais dura, podendo não apresentar efeito em bovinos que produzem carne macia (Montgomery et al., 2002), como foi o caso deste estudo, que utilizou bovinos ainda jovens.

Não houve efeito do período de maturação para PPC. Porém, de acordo com os valores de FC e MFI, a carne apresentou-se macia, quando foi maturada (Tabela 3). Isso provavelmente ocorreu, porque as enzimas cálcio-dependentes promovem uma série de alterações no tecido muscular, causando uma diminuição da rigidez e aumento gradativo da maciez da carne. De acordo com os resultados encontrados por Scanga et 
al. (2001) e Pedreira et al. (2003). Contudo, de acordo com o presente trabalho, os índices de MFI foram acima ou igual a 60, sendo considerados como músculos muito macios, independente da raça e suplementação. Apenas, a carne sem maturação, apresentou valor menor que 60 .

Vale ressaltar ainda, que houve interação entre grupos genéticos e dias de maturação para MFI (Figura 1). Os animais CC e NE apresentaram diferença no dia zero (período sem maturação), porém aos sete dias de maturação, esta diferença desapareceu, ou seja, os valores de MFI entre NE e CC se aproximaram. Concluindo que, o período de maturação alterou mais significativamente a maciez da carne de bovinos NE do que a de bovinos $\mathrm{CC}$. Isso possivelmente ocorreu, pelo fato do íon cálcio ser um agente regulador do sistema contrátil, sendo atuante no processo de maturação, podendo influenciar mais expressivamente no processo de maturação de animais que tendem a apresentar carne menos macia, como o NE.

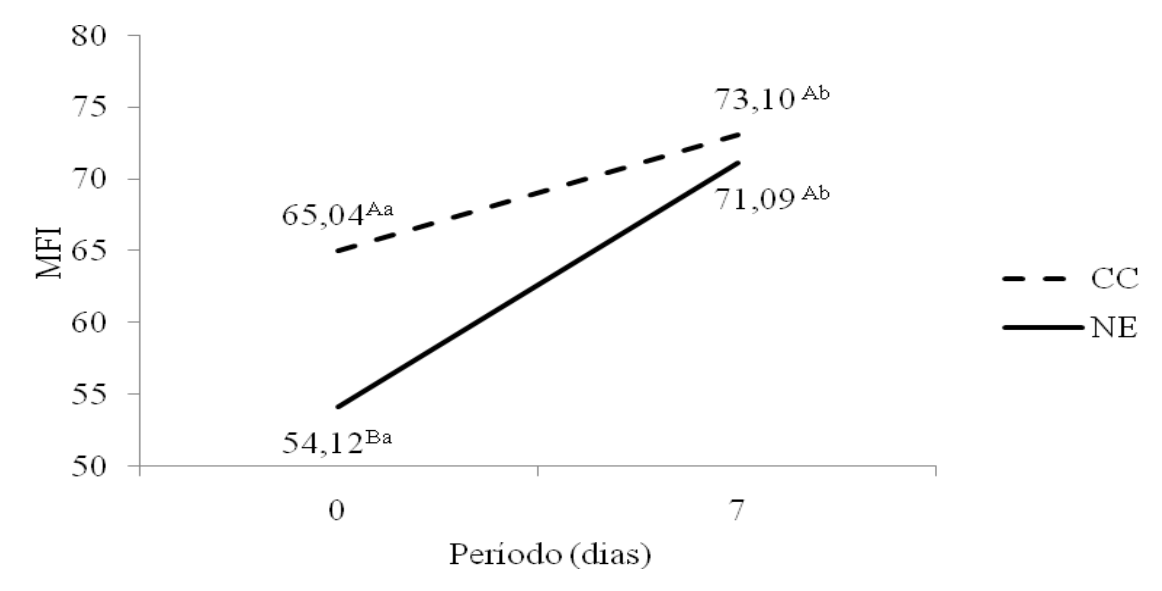

${ }^{\mathrm{a}, \mathrm{b}} \mathrm{Na}$ linha, médias seguidas de diferentes sobrescritos diferem $(\mathrm{P}<0,05)$.

${ }^{\mathrm{A}, \mathrm{B}} \mathrm{Na}$ coluna, médias seguidas de diferentes sobrescritos diferem $(\mathrm{P}<0,05)$.

Figura 1. Interação entre grupos genéticos (Canchim e Nelore) e dias de maturação (0 e 7) para MFI.

Não houve efeito do grupo genético, durante a exposição da carne sob condições simuladas de varejo, para os valores de $\mathrm{pH}$ e croma $\mathrm{a}^{*}$, exceto para os valores de croma 
$\mathrm{L}^{*} \mathrm{e} \mathrm{b}^{*}$, onde os animais NE apresentaram maior valor que os animais CC (Tabela 4).

Quanto maior o valor de $\mathrm{L}^{*}$, maior a luminosidade, demonstrando que a carne do NE perdeu mais água para a superfície, diminuindo a capacidade de reter a água interna, tornando-se menos suculenta e conseqüentemente mais dura, concordando com os dados de maciez (SF e MFI) encontrados.

Não houve efeito de suplementação das vitaminas D e E, durante a exposição da carne sob condições simuladas de varejo, para nenhuma das variáveis $\left(\mathrm{pH}, \mathrm{L}^{*}, \mathrm{a}^{*} \mathrm{e} \mathrm{b}^{*}\right)$ avaliadas (Tabela 4).

Tabela 4. Características de pH e coloração do músculo Longissimus de novilhos Nelore e Canchim suplementados ou não com vitaminas D e E

\begin{tabular}{cccccccc}
\hline & \multicolumn{3}{c}{$\mathrm{GG}^{2}$} & \multicolumn{3}{c}{ VIT $^{3}$} & \multicolumn{2}{c}{ Valor de P } & EPM $^{4}$ \\
\hline Item $^{1}$ & $\mathrm{NE}$ & $\mathrm{CC}$ & $\mathrm{CV}$ & $\mathrm{SV}$ & $\mathrm{GG}$ & $\mathrm{VIT}$ & \\
\hline $\mathrm{pH}$ & 5,54 & 5,63 & 5,65 & 5,52 & 0,19 & 0,11 & 0,05 \\
$\mathrm{~L} *$ & 40,85 & 39,08 & 39,95 & 39,99 & 0,04 & 0,96 & 0,60 \\
$\mathrm{a}^{*}$ & 15,24 & 15,06 & 15,27 & 15,02 & 0,69 & 0,59 & 0,33 \\
$\mathrm{~b}^{*}$ & 13,57 & 12,76 & 13,21 & 13,12 & 0,04 & 0,81 & 0,27
\end{tabular}

\footnotetext{
${ }^{\dagger}$ As médias referentes aos períodos encontram na tabela 5 .

${ }^{1} \mathrm{~L}^{*}$ : croma associado a luminosidade; $\mathrm{a}^{*}$ : croma que varia do verde (-) ao vermelho $(+) ; b^{*}$ : croma que varia do azul(-) ao amarelo $(+)$.

${ }^{2}$ GG: grupo genético; NE: Nelore; CC: Canchim.

${ }^{3}$ VIT: vitamina; CV: com suplementação de vitamina; SV: sem suplementação de vitamina. ${ }^{4}$ EPM: Erro Padrão Médio.
}

No entanto, para efeito de período durante a exposição da carne sob condições simuladas de varejo, foi observada diferença para todas as variáveis estudadas $\left(\mathrm{pH}, \mathrm{L}^{*}\right.$, $a^{*}$ e $\left.b^{*}\right)$, sendo que, os efeitos de período foram analisados por contraste linear, comparando-se P0 vs. P1, P0 vs. P2, e assim sucessivamente, até P0 vs. P7, para verificar em qual período se iniciou o processo de deterioração da carne (Tabela 5).

Como não foram observadas interações, os contrastes somente incluíram comparações entre as médias do efeito de período. 
Para $\mathrm{pH}$ e L*, quando analisados por contraste, os valores apresentaram diferença nas comparações entre P0 vs. P6 e P0 vs. P7. Já para $\mathrm{a}^{*} \mathrm{e} \mathrm{b}^{*}$, houve diferença, nas comparações entre todos os períodos (P0 vs. P1, P0 vs. P2, P0 vs. P3, P0 vs. P6 e P0 vs. P7) (Tabela 5).

Tabela 5. Contrastes para os valores de $\mathrm{pH}$ e cor ( $\mathrm{L}^{*}, \mathrm{a}^{*}$ e b*) do músculo Longissimus de novilhos, exposto sob condições simuladas de varejo, realizados nos períodos zero (P0), um (P1), dois (P2), três (P3), seis (P6) e sete (P7)

\begin{tabular}{ccccc}
\hline Item $^{1}$ & $\mathrm{pH}$ & $\mathrm{L}^{*}$ & $\mathrm{a}^{*}$ & $\mathrm{~b}^{*}$ \\
\hline Períodos $^{2}$ & \multicolumn{5}{c}{ Médias } \\
\hline P0 & 5,54 & 40,34 & 15,21 & 13,04 \\
P1 & 5,44 & 40,91 & 17,94 & 14,79 \\
P2 & 5,50 & 41,06 & 17,29 & 14,72 \\
P3 & 5,51 & 40,76 & 16,74 & 14,55 \\
P6 & 5,70 & 38,92 & 12,35 & 12,25 \\
P7 & 5,80 & 37,82 & 11,36 & 9,64 \\
\hline
\end{tabular}

Contrastes (valor de P)

\begin{tabular}{lcccc}
\hline P0 vs. P1 & 0,13 & 0,43 & $<0,01$ & $<0,01$ \\
P0 vs. P2 & 0,57 & 0,31 & $<0,01$ & $<0,01$ \\
P0 vs. P3 & 0,68 & 0,58 & $<0,01$ & $<0,01$ \\
P0 vs. P6 & 0,02 & 0,04 & $<0,01$ & 0,04 \\
P0 vs. P7 & $<0,01$ & $<0,01$ & $<0,01$ & $<0,01$
\end{tabular}

${ }^{1} \mathrm{~L}^{*}$ : croma associado a luminosidade; $\mathrm{a}^{*}$ : croma que varia do verde (-) ao vermelho $(+) ; \mathrm{b}^{*}$ : croma que varia do azul(-) ao amarelo (+).

${ }^{2}$ Período zero $(\mathrm{P} 0)$, período um $(\mathrm{P} 1)$, período dois $(\mathrm{P} 2)$, período três $(\mathrm{P} 3)$, período seis $(\mathrm{P} 6)$ e período sete $(\mathrm{P} 7)$.

Os valores de $\mathrm{pH}$, independente do período de exposição sob condições simuladas de varejo, encontram-se dentro do aceitável, abaixo de 6,0 (Tabela 5).

Possivelmente, um ligeiro aumento nos valores de $\mathrm{L}^{*}$, nos primeiros dias de exposição sob condições simuladas de varejo, foi causado pelas perdas de água por exsudação (PAE), porém esta perda não foi mensurada. Os valores de L* encontrados 
foram entre 37,82 e 41,06 (Tabela 5), sendo abaixo dos valores encontrados por Pereira (2002), entre 41 e 52. Essa diferença nos valores de L* encontrados no presente estudo pode ser explicada pelo uso de animais jovens, pois novilhos apresentam carne mais clara que animais com idade mais avançada, que foi o caso do estudo de Pereira (2002), que utilizou animais com 30 meses. De acordo com Miller et al. (2001), com o avanço da idade a mioglobina retém $\mathrm{O}_{2}$ no músculo, se tornando menos eficiente. Com isso, o organismo acaba produzindo níveis elevados de mioglobina para compensar, tornando a carne mais escura.

Os valores de $\mathrm{a}^{*}$ e $\mathrm{b}^{*}$ foram consideravelmente reduzidos no P6 e P7 (Tabela 5). Isso pode ter ocorrido, pois com o passar do tempo, inicia-se o processo de oxidação da cor e os valores de a* podem diminuir, sendo equivalente, a uma carne de coloração mais marrom.

Em pesquisa na literatura, trabalhos evidenciaram que carnes frescas embaladas em filme de PVC e expostas sob iluminação, duram aproximadamente sete dias, após esse período, já começam a deteriorar, havendo grandes alterações de coloração (Gray et al., 1996; Sanders et al. 1997) e carnes exposta sob condições simuladas de varejo mantém-se própria para consumo com até 3 dias de exposição, de acordo com os dados encontrados, que à partir do P3, apresentaram diferenças nos valores encontrados.

A partir do P6, as amostras apresentavam-se com fortes odores e aspecto visual inaceitável para o consumo, por isso optou-se por descartar as amostras e encerrar as análises da carne exposta sob condições simuladas de varejo. Provavelmente, estas mudanças nas variáveis observadas, ocorreram em função de contaminação microbiológica, porém esta variável não foi avaliada.

Não houve efeito de suplementação de vitaminas D e E para a concentração de vitamina D e E no músculo Longissimus (Tabela 6). Houve efeito de grupo genético, 
onde os animais NE apresentaram maior concentração de Vit D e Vit E em relação aos animais CC (Tabela 6). Para Vit D, a concentração da forma ativa da vitamina D $\left(1,25(\mathrm{OH})_{2} \mathrm{D}\right)$ no plasma e em diferentes tecidos tendem a ser maior em Bos indicus que em Bos taurus. Esta diferença no armazenamento de $1,25(\mathrm{OH})_{2} \mathrm{D}$ no tecido pode ser atribuída à adaptação genética ao ambiente com luz solar do Bos indicus comparado ao Bos taurus, sendo assim os animais Bos indicus apresentam um metabolismo mais eficiente para armazenar a forma ativa da vitamina D (Montgomery et al., 2004).

Tabela 6. Concentração final de vitamina D e vitamina E no músculo Longissimus de novilhos suplementados ou não com vitaminas D e E $(\mathrm{mg} / \mathrm{kg})$

\begin{tabular}{lccccccc}
\hline & \multicolumn{2}{c}{$\mathrm{GG}^{2}$} & \multicolumn{2}{c}{$\mathrm{VIT}^{3}$} & \multicolumn{2}{c}{ Valor de P } & \multirow{2}{*}{$\mathrm{EPM}^{4}$} \\
\hline Item & $\mathrm{NE}$ & $\mathrm{CC}$ & $\mathrm{CV}$ & $\mathrm{SV}$ & $\mathrm{GG}$ & $\mathrm{VIT}$ & - \\
\hline Vit D & 0,19 & 0,03 & 0,18 & 0,04 & 0,01 & 0,24 & 0,63 \\
Vit E & 2,88 & 1,29 & 1,59 & 2,57 & 0,01 & 0,06 & 0,39 \\
\hline
\end{tabular}

\footnotetext{
Vit D: concentração de vitamina $\mathrm{D}_{3}$ no Longissimus $(\mathrm{mg} / \mathrm{kg})$; Vit E: concentração de acetato de $\alpha$-tocoferol no Longissimus ( $\mathrm{mg} / \mathrm{kg}$ ).

${ }^{2}$ GG: grupo genético; NE: Nelore; CC: Canchim.

${ }^{3}$ VIT: Vitamina; CV: com vitamina; SV: sem vitamina.

EPM: Erro Padrão Médio.
}

Para Vit E, os animais NE são mais seletivos para o consumo de volumoso, quando estão consumindo dietas de alto concentrado, como foi observado no presente experimento, que durante a terminação estes animais estavam com $80 \%$ de concentrado. Observando-se as sobras no cocho dos animais NE, pode-se notar que estes consumiam todo o volumoso e as sobras eram compostas apenas por concentrado. Portanto, um maior uso de volumoso secos em dietas de terminação (feno de capim Coast- cross), aliada a seletividade do NE, presumidamente teria como resultado maiores concentrações basais de precursores de vitamina E, e com isso a concentração muscular poderia ser maior. 
Não houve efeito de suplementação de vitaminas D e E, para nenhum dos ácidos graxos estudados (Tabela 7). Contudo, como o efeito principal para esta análise é a suplementação de vitaminas $\mathrm{D}$ e E, e esta não teve diferença, então as interações entre grupo genético e suplementação de vitaminas D e E, e os efeitos isolados de grupo genético e período, não foram discutidos. No geral, pode-se concluir, que a suplementação das vitaminas D e E manteve o perfil de ácidos graxos nas amostras expostas sob condições simuladas de varejo por sete dias, possivelmente resistindo ao processo de oxidação. 
in

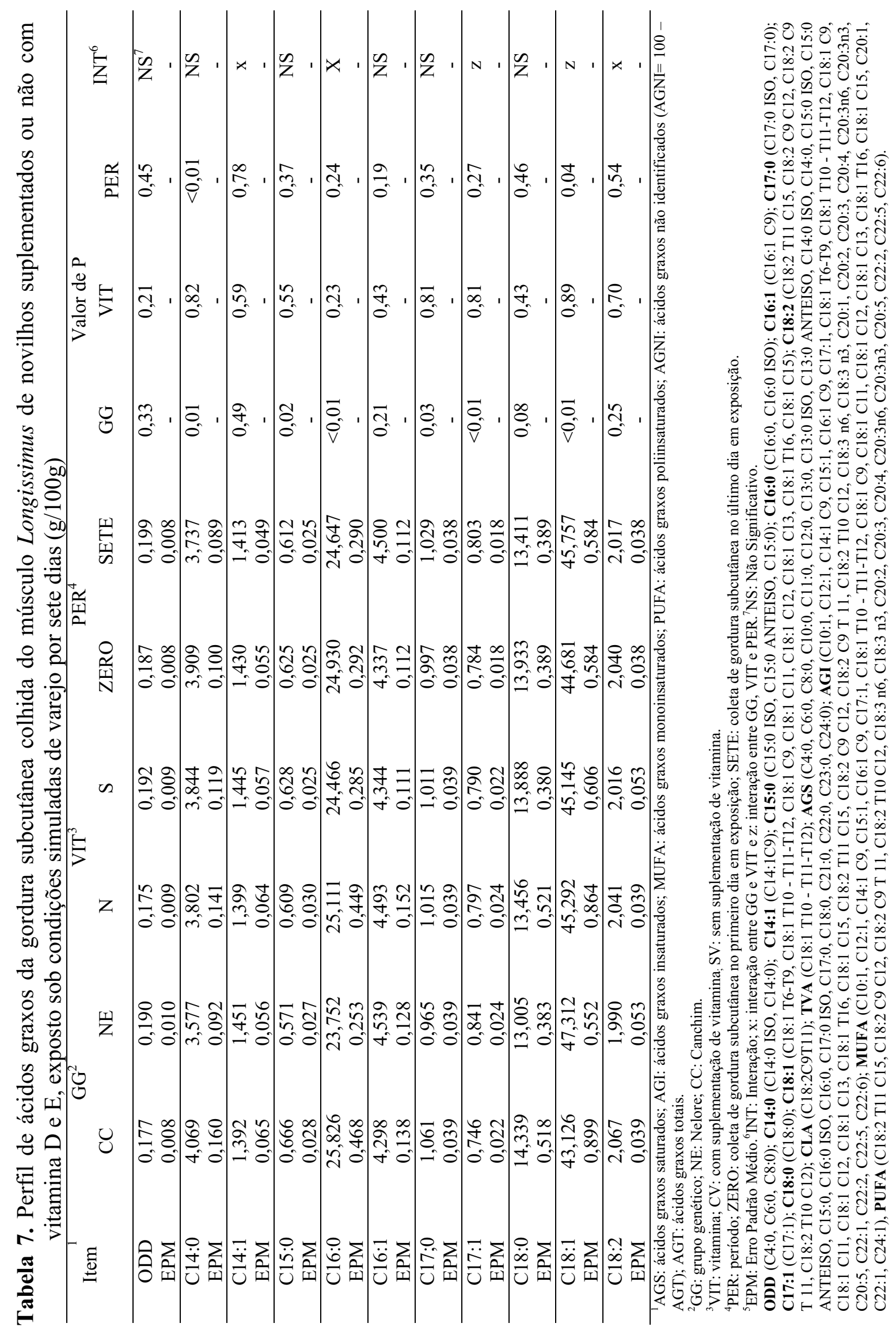




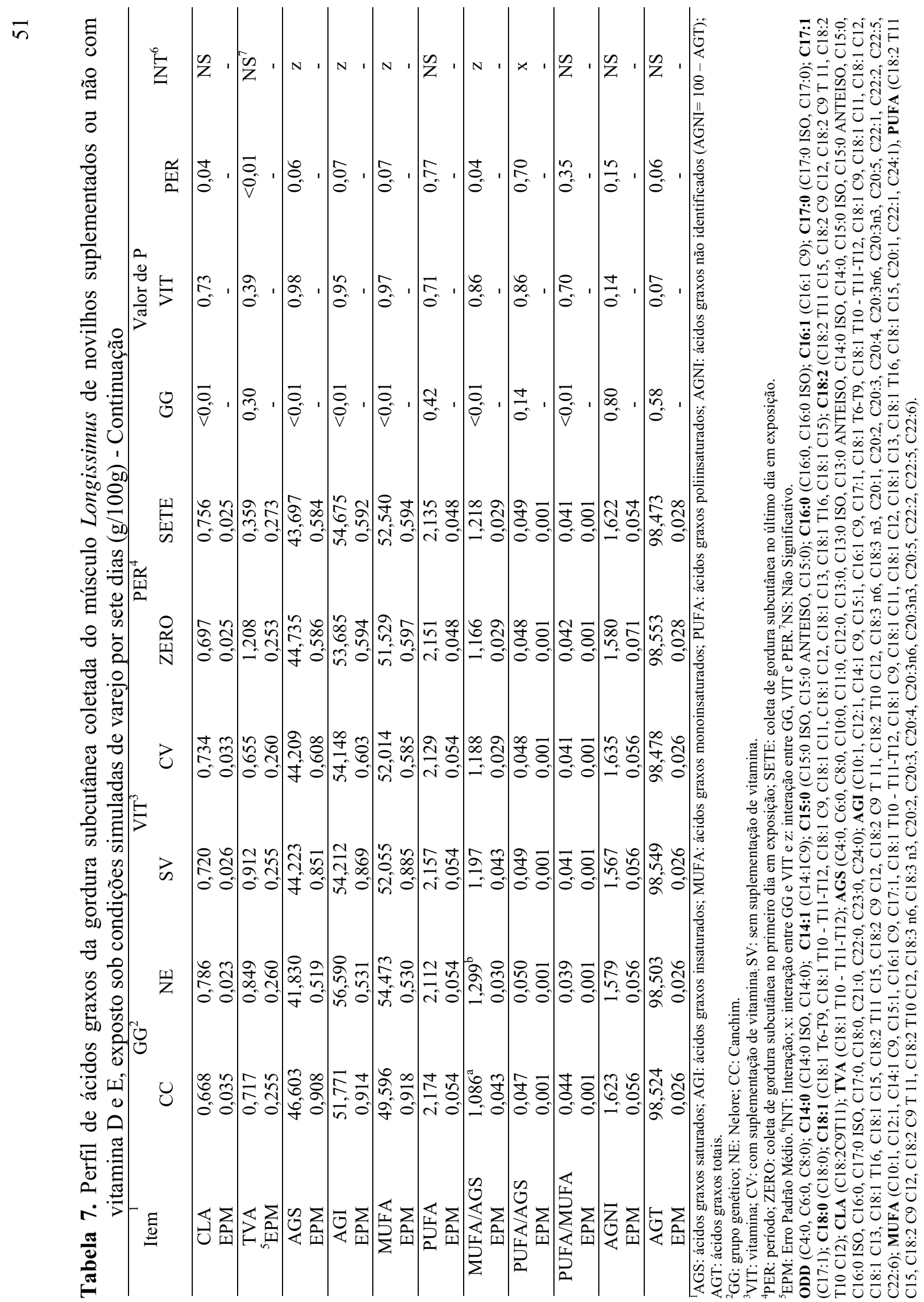




\section{Conclusão}

A suplementação das vitaminas D e E não interferiu no desempenho, características de carcaça e atributos de qualidade da carne de bovinos jovens confinados.

A suplementação de vitaminas D e E, pode ser efetiva para melhorar a maciez da carne, quando bovinos tendem a apresentar carne mais dura, podendo não apresentar efeito em bovinos que produzem carne macia, apesar de ser efetiva para aumentar os níveis de cálcio plasmático.

A suplementação de vitamina D e E não promoveu a estabilidade da cor da carne exposta sob condições simuladas de varejo.

A suplementação de vitamina D e E manteve o perfil de ácidos graxos durante o período de exposição sob condições simuladas de varejo. 


\section{Referência Bibliográfica}

ASSOCIAÇÃO BRASILEIRA DAS INDÚSTRIAS EXPORTADORAS DE CARNE. Disponível em: <www.abiec.com.br $>$. acesso em: 05 Jan 2010.

BLIGH, E.G.; DYER, W.J. A rapid method of total lipid extraction and purification. Journal Biochemistry and Physiology, Canadian. v. 37, p. 911, 1959.

CHRISTIE, W.W. Simple produce for rapid transmethy lation of glycerolipids and cholesteryl esters. Journal of Lipid Research. v. 23, p. 1-4, 1982.

CULLER, R.D.; PARRISH, J.R.F.C.; SMITH, G.C. Realtionship of myofibril fragmentation index to certain chemical physical and sensory characteristics of bovine longissimus muscle. Journal Food Science. v. 43, p. 1177, 1978.

FAUSTMAN, C.; CASSENS, R.G.; SCHAEFER, D.M. et al. Improvement of pigment and lipid estability in holstein steers beef by dietary supplementation with vitamin E. Journal of Food Science. v. 54, p. 858-862, 1989.

GONG, B.Y.; HO, J.W. Simultaneous separation and detection of ten common fatsoluble vitamins in milk. Journal Liquid Chromatography Relations Technology. v. 20, p. 2389-2397, 1997.

GRAY, J.I.; GOMAA, E.A.; BUCKLEY, D.J. Oxidative Quality and Shelf Life of Meats. Meat Science, v. 43, p. 111-123, 1996.

HARA, A.; RANDIN, N.S. Lipid extraticion of tissues with a low toxicity solvent. Anal Biochemical. v. 90, p. 420-426, 1978.

MENEZES, L.F.G.; RESTLE, J.; VAZ, F.N. et al. Composição Física da Carcaça e Qualidade da Carne de Novilhos de Gerações Avançadas do cruzamento Alternado entre as Raças Charolês e Nelore, Terminados em Confinamento. Revista Brasileira de Zootecnia, v. 34, n. 3, p. 946-956, 2005.

MILLER, M.F., CARR, M.A., RAMSEY, C.B. et al. Consumer thresholds for establishing the value of beef tenderness. Journal of Animal Science. v. 79, p. 3062-3068, 2001.

MONTGOMERY, J.L.; CARR, M.A.; KERTH, C.R. et al.. Effect of vitamin D3 supplementation level on the postmortem tenderization of beef from steers. Journal of Animal Science. v. 80, n. 4, p. 971-981, 2002.

MONTGOMERY, J.L.; KING, M.B.; GENTRY, J.G. Supplemental vitamin D3 concentration and biological type of steers. Journal of Animal Science. v. 82, p. 2092-2104, 2004.

MONTGOMERY, J.L.; PARRISH JR., F.C.; BEITZ, D.C. et al. The use of vitamin $\mathrm{D}_{3}$ to improve beef tenderness. Journal of Animal Science. v. 78, p. 2615-2621, 2000a.

PEDREIRA, A.C.M.S.; Luchiari Filho, A.; Leite, V.B.O. et al. Quality characteristics of Longissimus dorsi muscle from Bos indicus animals treated whit Vitamin $D_{3}$. Scientia Agricola. v. 60, n. 4, p. 637-642, 2003.

PEREIRA, A.S.C. Qualidade de carne de bovines Nelore (Bos Taurus indicus) suplementados com vitamina E. 2002. 83f. Dissertação de Mestrado, FZEA_USP, Pirassununga, 2002.

SANDERS, S.K.; MORGAN, J.B.; WULF, D.M.; et al. Vitamin E supplementation of cattle and shelf-life of beef for the Japanese market. Journal of Animal Science. v. 75, p. 2634-2640, 1997.

SAS. SAS User's Guide: Statistics. SAS Inst. Inc., Cary, NC, 2003.

SCANGA, J.A.; BELK, K.E.; TATUM, J.D. et al. Supranutritional oral supplementation with vitamin D3 and calcium and the effects on beef tenderness. Journal of Animal Science. v. 79, n. 4, p. 912-918, 2001. 
SWANEK, S.S.; MORGAN, J.B.; OWENS, F.N. et al. Vitamin D3 supplementation of beef steers increases longissimus tenderness. Journal of Animal Science. v. 77, p. 874-881, 1999.

VARGAS, D.N.; DOWN, A.E.; WEBB, D.S. et al. Effects of dietary supplementation of feedlot steers with vitamins E and D3 on live performance, carcass traits, shelf-life attributes and Longissimus muscle tenderness. Animal Science Research Report, Oklahoma State University, p.59-66, 1999a.

WHEELER, T. L.; SHACKELFORD, S.D.; JOHNSON, L.P., et al. A comparison of Warner- Bratzler shear force assessment within and among institutions. Journal of Animal Science. v. 75, p. 2423-2432, 1997. 
CAPÍTULO 3 


\section{Implicações}

Devem-se conduzir outras pesquisas, avaliando a oxidação pela análise do ácido tiobarbitúrico (TBARS), para quantificar a oxidação.

Devem-se conduzir outras pesquisas, realizando a análise microbiológica destas carnes.

São necessários mais estudos em relação a doses e duração da suplementação, tanto para vitamina $\mathrm{D}$, quanto para a vitamina $\mathrm{E}$, visto que os estudos existentes apresentam muitos resultados contraditórios.

Além disso, o custo da suplementação está em torno de $\mathrm{R} \$ 4,94 /$ cab para vitamina E e $R \$ 2,22 /$ cab para vitamina $\mathrm{D}_{3}$ (considerando o valor do dólar comercial a $\mathrm{R} \$ 1,73$ ), sendo que este custo é considerado alto, visto que hoje apenas uma pequena parte do mercado, recebe por qualidade. 